Letícia Canut $^{1}$

\title{
OPERACIONALIZAÇÃO DO SISTEMA ÚNICO DE SAÚDE E DE SUA ASSISTÊNCIA FARMACÊUTICA DIANTE DA JUDICIALIZAÇÃO: UM ESTUDO DE CASO NO MUNICÍPIO DE SÃO JOSÉ/SC*
}

Operationalization of the Brazilian National Health System and its pharmacy assistance in face of judicialization: a case study in the Municipality of São José, State of Santa Catarina

${ }^{1}$ Centro Universitário Estácio Santa Catarina. Florianópolis/SC, Brasil.

Correspondência: Letícia Canut. E-mail: leticiacanut@hotmail.com.

*Esta pesquisa foi financiada pelo Centro Universitário Estácio Santa Catarina, dentro do Programa de Pesquisa Docente (PPD). O Município de São José foi escolhido por estar inserido na realidade política, social e espacial da instituição.

Recebido em: 09/09/2016. Revisado: 06/02/2017. Revisado novamente: 13/03/2017. Aprovado: 17/03/2017. 


\section{RESUMO}

O presente trabalho baseia-se na premissa de que o Judiciário tem efetivado o direito à saúde sem observância das políticas públicas do setor e na identificação de efeitos negativos dessa judicialização sobre a operacionalização do Sistema Único de Saúde e de sua assistência farmacêutica. Assim procura verificar de que forma esses efeitos negativos da judicialização têm se manifestado nas decisões que condenam o Município de São José (SC) a fornecer medicamentos. Para enfrentar o problema apresentado, selecionaram-se as decisões prolatadas no período de 01/09/2013 a 31/08/2015 pelo Tribunal de Justiça de Santa Catarina, por meio de acórdãos e decisões monocráticas em apelações cíveis interpostas pelo Município de São José. Primeiramente, fez-se necessário explicar a relação entre o direito fundamental à saúde e a sistemática de operacionalização do Sistema Único de Saúde e de sua assistência farmacêutica, incluindo a realidade do município estudado. Na sequência, foram sistematizados os efeitos - positivos e negativos - da judicialização sobre tal operacionalização para, uma vez confirmada a premissa da não aplicação das políticas públicas do setor, verificar como os efeitos negativos sistematizados no trabalho estavam refletidos nas decisões examinadas. Ao final, foi possível identificar e apontar como tais efeitos se manifestaram nas decisões do tribunal catarinense, confirmando um cenário em que a atuação judicial colabora para a desorganização e desestruturação do sistema público de saúde brasileiro e a necessidade de que o Judiciário passe a atuar de forma a fazer com que este sistema funcione como um Sistema Único de Saúde.

\section{Palavras-Chave}

Assistência Farmacêutica; Direito à Saúde; Judicialização; Município de São José/SC; Sistema Único de Saúde.

\section{ABSTRACT}

The present study based on the premise that the Judiciary Branch has enforced the right to health without observance to the public policies of the sector and the identification of negative effects of this judicialization on the operationalization of the Brazilian National Health System and its pharmacy assistance. It attempts to find out in what ways these negative effects are exposed in the decision through which the Municipality of São José (State of Santa Catarina) was forced to supply medicines. To deal with this problem, decisions were selected among those enacted from 09/01/2013 to 08/31/2015 by the Court of Justice of Santa Catarina by means of collective and monocratic court rulings, in response to civil appeals filed by the Municipality of São José. Firstly, it is necessary to explain the relationship between the fundamental right to health and the system of operationalization of the Brazilian National Health System and its pharmacy service, including the circumstances of the municipality studied. Further on, the positive and negative effects of judicialization on this operationalization were systematized to verify-once confirmed the premise of the non-application of the public policies of the area- how those effects mirrored the decisions examined. At the end, it was possible to identify and point out how these negative effects were reflected in the court decisions, confirming a scenario in which judicial action contributes to disorganize and disrupt the Brazilian National Health System, and made evident the need for judiciary actions to be carried out in a way to allow the system to work as a public national health system.

\section{Keywords}

Brazilian National Health System; Judicialization; Municipality of São José (SC); Pharmacy Assistance; Right to Health. 


\section{Introdução}

O novo constitucionalismo, introduzido pela Constituição Federal de $1988^{1}$ $(\mathrm{CF} / 88)$, transformou radicalmente as sistemáticas política e jurídica do direito à saúde ao reconhecê-lo como um direito fundamental social (artigo $6^{\circ} \mathrm{da} \mathrm{CF} / 88$ ) - com força normativa e aplicabilidade imediata, na esteira dos demais direitos fundamentais (artigo $5^{\circ}$, parágrafo $1^{\circ}$, da $\mathrm{CF} / 88$ ) - a ser garantido a todos pelo Estado, por meio de políticas públicas implementadas no âmbito do SUS (artigos 196 e 198 da CF/88).

A partir da constatação de que o Judiciário tem efetivado o direito à saúde sem observância das políticas públicas do setor e de que a judicialização da saúde apresenta efeitos positivos e negativos sobre a operacionalização do Sistema Único de Saúde (SUS) e de sua assistência Farmacêutica (AF), o presente trabalho pretende verificar de que forma os efeitos negativos desse fenômeno têm tido reflexo nas decisões que condenam o Município de São José (SC) a fornecer medicamentos.

\section{Metodologia}

Delimitou-se o estudo à $\mathrm{AF}$ em razão de a totalidade das demandas examinadas terem tido como objeto o pedido de medicamentos, embora houvesse decisões relacionadas a outro tipo de solicitação. Optou-se por analisar as decisões contra o Município de São José no âmbito da Justiça Estadual Comum, excluindo-se, assim, todas as ações em que o município foi demandado em conjunto com a União e as causas de competência dos Juizados Especiais da Fazenda Pública²

A partir dessa delimitação, selecionou-se uma metodologia para a pesquisa. Descartou-se a possibilidade de conseguir a identificação e o acesso aos autos dos processos decididos contra o Município de São José no período selecionado. Tais dados permitiriam o conhecimento do panorama da judicialização da saúde, especialmente em primeira instância, com identificação das ações que foram solucionadas definitivamente em primeiro grau, as que foram objeto de recurso e, ainda, aquelas de competência originária do Tribunal de Justiça de Santa Catarina (TJSC).

Assim, restringiu-se a pesquisa à análise das decisões prolatadas pelo TJSC nos recursos de apelação cível que tiveram o Município de São José como apelante. A coleta das decisões foi feita na página eletrônica do TJSC de acordo com os seguintes critérios de busca: na opção jurisprudência, em "busca avançada”, elegeu-se

${ }^{1}$ BRASIL. Constituição da República Federativa do Brasil de 1988. Disponível em: <http://www.planalto.gov. br/ccivil_03/constituicao/constituicaocompilado.htm>. Acesso em: 13 out. 2017.

${ }^{2}$ Esses juizados possuem legislação própria que regula não só sua competência, mas também quem pode ser autor e réu perante os mesmos. BRASIL Lei 12.153, de 22 de dezembro de 2009. Dispõe sobre os Juizados Especiais da Fazenda Pública no âmbito dos Estados, do Distrito Federal, dos Territórios e dos Municípios. Disponível em: <http://www.planalto.gov.br/ccivil_03/_Ato2007-2010/2009/Lei/L12153. htm>. Acesso em: 13 out. 2017. 
"inteiro teor" como "abrangência da busca", e os resultados foram buscados "direito à saúde SUS” (“com todas as palavras"), no período "de 01/09/2013 a 31/08/2015", "Comarca de São José” e órgão julgador "todos”. Foi feita uma busca por "acórdãos do Tribunal", da qual resultaram 19 acórdãos em apelações cíveis, e outra busca com os mesmos critérios, mas com a opção por "decisões monocráticas do Tribunal de Justiça”, da qual obtiveram-se 18 decisões monocráticas em apelações cíveis.

Dessa forma, o material examinado consistirá em 37 deciões do TJSC, prolatadas no período de $1^{\circ}$ de setembro de 2013 a 31 de agosto de 2015 (período escolhido aleatoriamente) em apelações cíveis interpostas pelo Município de São José, coletadas de acordo com os critérios ora citados.

\section{Direito fundamental à saúde e a operacionalização do SUS}

Além de institucionalizar o SUS, a CF/88 estabeleceu suas diretrizes operacionais e seus princípios, especificados nas Leis ns. 8.080/1990 e 8.142/19903. As diretrizes são a descentralização, com direção única em cada esfera de governo; a regionalização e hierarquização; e a participação da comunidade (artigo 198, caput e incisos, da CF/88). Já os princípios são o da universalidade, da equidade e da integralidade (artigo $196 \mathrm{da} C F / 88$ ), que se materializam à medida que o SUS se concretiza orientado por suas diretrizes.

A diretriz da descentralização ${ }^{4}$ diz respeito à distribuição de competências entre os entes federativos, que são autônomos e contam com gestores de saúde em cada esfera de poder (artigo 9º, incisos I a III, da Lei n. 8.080/1990). A descentralização pode seguir o caminho da municipalização e o da regionalização e hierarquização (artigo 7º, inciso IX, da Lei n. 8.080/1990). A regionalização se estrutura com base na diretriz da hierarquização, que traduz a organização do sistema de saúde de forma a garantir a todos o acesso a todos os níveis de complexidade ${ }^{5}$ desde a atenção básica até os tratamentos de média e alta complexidade, voltando-se para

\footnotetext{
${ }^{3}$ BRASIL. Lei 8.080, de 19 de setembro de 1990. Dispõe sobre as condições para a promoção, proteção e recuperação da saúde, a organização e o funcionamento dos serviços correspondentes e dá outras providências. Disponível em: < http://www.planalto.gov.br/ccivil_03/leis/L8080.htm>. Acesso em: 13 out. 2017. BRASIL. Lei 8.142, de 28 de dezembro de 1990. Dispõe sobre a participação da comunidade na gestão do Sistema Único de Saúde (SUS) e sobre as transferências intergovernamentais de recursos financeiros na área da saúde e dá outras providências. Disponível em: <http://www.planalto.gov.br/ ccivil_03/leis/L8142.htm>. Acesso em: 13 out. 2017.

${ }^{4}$ Prevista, também, nos artigos $7^{\circ}$, inciso IX, e $9^{\circ}$, incisos I a III, da Lei n. 8.080/1990. BRASIL. Lei 8.080, de 19 de setembro de 1990, cit.

${ }^{5}$ Essa diretriz envolve o tema das portas de entrada do SUS, tratado no artigo $9^{\circ}$, do Decreto n. 7.508/2011. BRASIL. Decreto 7.508, de 28 de junho de 2011. Regulamenta a Lei no8.080, de 19 de setembro de 1990, para dispor sobre a organização do Sistema Único de Saúde - SUS, o planejamento da saúde, a assistência à saúde e a articulação interfederativa, e dá outras providências. Disponível em: <http://www.planalto.gov. br/ccivil_03/_ato2011-2014/2011/decreto/D7508.htm>. Acesso em: 13 out. 2017.
} 
a garantia do princípio da integralidade da assistência à saúde ${ }^{6}$ e, também, da universalidade e da equidade.

Assim, "a integralidade da assistência à saúde se inicia e se completa na Rede de Atenção à Saúde, mediante referenciamento do usuário na rede regional e interestadual, conforme pactuado nas Comissões Intergestores" (artigo 20, do Decreto n. 7.508/2011).Por isso, o princípio da integralidade deve ser garantido no “âmbito do sistema de saúde, e não no âmbito de cada ente federativo”. Trata-se de "solidariedade ao sistema"7.

Já a diretriz de participação da comunidade ${ }^{8}$ garante que as políticas do SUS sejam concebidas, formuladas, implementadas e avaliadas de forma participativa.

Esses elementos viabilizam a análise da operacionalização do SUS sob uma perspectiva geral e abstrata. Isso porque a $\mathrm{CF} / 88$ prevê a abrangência do direito à saúde (artigos 196 e 198, inciso II,da CF/88) de forma genérica, sem estabelecer quais prestações ou serviços de saúde devem ser disponibilizados no SUS ${ }^{9}$ e sem se ocupar em definir a competência de cada ente federativo para serviços ou prestações concretos de saúde, remetendo somente à responsabilidade dos entes federativos para o desempenho da competência comum ${ }^{10}$ de cuidar da saúde(artigo 22, inciso II, da CF/88) ${ }^{11}$. As Leis n. 8080/1990 ${ }^{12}$ e n. 8142/1990 não foram suficientes para fazer tais estipulações de forma mais especificada.

Foram e vão sendo editadas normas que, ao definirem o conteúdo do direito à saúde, as atribuições e estruturas do SUS, passam a especificar a sistemática de sua operacionalização, como exemplo: normas operacionais (NOBs) e normas de assistência à saúde (NOAs); o Pacto pela Saúde de $2006^{13}$; o Decreto n. 7.508/2011 ${ }^{14}$; além de todas as leis e portarias que estabelecem o conteúdo específico do direito à saúde -como as normas de AF, as de atenção hospitalar etc., e as pactuações inter-

${ }^{6}$ SANTOS, Lenir. O princípio da solidariedade no SUS. Blog o Direito Sanitário: saúde e cidadania. Disponível em: <http://blogs.bvsalud.org/ds/2011/09/30/o-principio-da-solidariedade-no-sus/>. Acesso em: 13 out. 2011.

${ }^{7}$ Id. Ibid.

${ }^{8}$ Essa diretriz é objeto da Lei n. 8.142/1990, que instituiu as conferências e conselhos de saúde. BRASIL. Lei n. 8.142/1990, de 28 de dezembro de 1990, cit.

9SARLET, Ingo Wolfgang. A eficácia dos direitos fundamentais: uma teoria geral dos direitos fundamentais na perspectiva constitucional. 10. ed. rev. atual. e ampl. Porto Alegre: Livr. do Advogado, 2010. p. $289-290$.

${ }^{10} \mathrm{AITH}$, Fernando. Curso de direito sanitário. A proteção do direito à saúde no Brasil. São Paulo: Quartier Latin, 2007. p. 361-362.

${ }^{11} \mathrm{O}$ parágrafo único deste artigo prevê que: “Leis complementares fixarão normas para a cooperação entre a União e os Estados, o Distrito Federal e os Municípios, tendo em vista o equilíbrio do desenvolvimento e do bem-estar em âmbito nacional". No entanto, ainda não foi editada essa regulamentação, impondo desafios para a concretização do sistema de saúde.

${ }^{12}$ A Lei n. 8.080/1990, artigos 15 a 19, faz referência às competências comuns e específicas de cada ente federativo, mas pouco esclarece sobre as responsabilidades de cada ente na organização de ações e serviços de saúde específicos. BRASIL. Lei n. 8.080, de 19 de setembro de 1990, cit.

${ }^{13}$ CONSELHO NACIONAL DE SAÚDE. Pactos pela saúde. Disponível em: <http://conselho.saude.gov.br/ webpacto/>. Acesso em: 13 out. 2017.

${ }^{14}$ BRASIL. Decreto 7.508, de 28 de junho de 2011, cit. 
gestores. Tais normas se somam ao arsenal do Direito Sanitário.Figuras peculiares nesse processo são as decisões das comissões intergestores ${ }^{15}$, que consistem em colegiados de negociação e deliberação sobre a implementação da política de saúde (artigo 32 do Decreto n. 7.508/2011) com atribuição de decidir sobre os aspectos operacionais do SUS ${ }^{16}$.

Nesse contexto, destaca-se a atuação dos poderes Legislativo e Executivo, pois eles vão definindo o conteúdo e as competências da área da saúde por meio de políticas públicas que se formalizam tanto em leis como em normas infralegais, de baixa hierarquia normativa - decretos, portarias, resoluções, pactuações intergestores (resoluções da Comissão Intergestores Tripartite - CIT, comissão intergestores estaduais - CIB, e regionais - CIR, o contrato organizativo de ação pública da saúde, previsto no artigo 33 do Decreto n. 7.508/2011)- e se materializam em ações, serviços e prestações de saúde.

Tais definições, ao serem feitas por políticas elaboradas no âmbito do SUS, seguem suas diretrizes e princípios, sendo formuladas e implementadas em um processo descentralizado, pautado na participação da comunidade - por meio das conferências e conselhos de saúde - e nas pactuações intergestores (comissões intergestores tripartite - CIT -, bipartite e regional), tendo em vista questões geográficas, socioeconômicas e epidemiológicas locais e regionais.

O SUS se operacionaliza de acordo com toda essa sistemática, e só no contexto dela é possível verificar que, para cada prestação de saúde - medicamentos, tratamentos, cirurgias etc. -, há regras específicas a serem cumpridas, especialmente de competência dos entes federativos.

Além disso, há de se ressaltar que o SUS não apresenta personalidade jurídica própria; é uma instituição composta por várias outras instituições jurídicas autônomas e complementares entre si - como o Ministério da Saúde; as secretarias estaduais e municipais de Saúde; as autarquias hospitalares; as autarquias especiais (agências reguladoras); as fundações; as conferências e os conselhos de saúde; fundos

\footnotetext{
${ }^{15}$ Ver CANUT, Letícia. Comissões Intergestores: inovação na descentralização das políticas de saúde. In: CUSTÓDIO, Ande Viana; VIEIRA, Reginaldo de Souza (Orgs.). Estado, política e direito políticas públicas e direitos sociais. Criciúma: UNESC, 2011. v. 3, p. 101-125. Tendo o tema sido atualizado em artigo posterior: CANUT, Letícia. Uma breve introdução ao SUS para compreensão do direito à saúde no Brasil. Revista Direitos Fundamentais \& Democracia (UniBrasil), Curitiba, v. 12, n. 12, p. 186-214, 196, 203208 jul./dez. 2012.Disponível em: <http://revistaeletronicardfd.unibrasil.com.br/index.php/rdfd/article/ viewFile/311/281> e na tese: CANUT, Letícia. Exercício do direito coletivo à saúde na pós-modernidade jurídico-política brasileira: nova estrutura participativa para a formulação das políticas do Sistema Único. 2013. Tese (Doutorado em Direito) - Programa de Pós-graduação em Direito- PPGD da Universidade Federal de Santa-Catarina, Florianópolis, 2013. p. 231-237.

${ }^{16}$ Nesse sentido, ver o artigo $2^{\circ}$, inciso IV, do Decreto n. 7.508/2011 (cit.) e o artigo 14-Ada Lei n. 8.080/1990 (cit.).
} 
de saúde ${ }^{17}$; e as comissões intergestores ${ }^{18}$, que se interconectam para desempenhar a função constitucional de garantir, por meio de políticas públicas, o direito de todos à saúde integral.

É por meio do SUS que se concretiza o direito à saúde, na dimensão individual e coletiva. Por isso, qualquer debate sobre esse direito deve considerar a perspectiva de sua operacionalização - aqui apresentada tão brevemente -, o que significa considerar sua capacidade de funcionamento adequado e conforme as previsões constitucional, legal e infralegal que o estruturam. Essa perspectiva se traduz na questão de fazer com que o SUS funcione como SUS, sendo este um compromisso a ser assumido por todos os titulares desse direito ${ }^{19}$.

Vários são os desafios a serem enfrentados para que o SUS corresponda às estipulações normativas, por exemplo: o baixo financiamento; a ausência de parâmetros que orientem o padrão de integralidade; a gestão pública insatisfatória; "a falta de sentimento de pertencimento da população com o direito à saúde[...]". Decorrendo dessas macrocausas, a judicialização da saúde ${ }^{20}$ reflete a contradição entre o SUS legal e o SUS real ${ }^{21}$.

\section{Uma visão geral da operacionalização da assistência farmacêutica do SUS}

Tratar da assistência farmacêutica $(\mathrm{AF})^{22}$ no SUS é considerar a sistemática e os elementos apresentados no tópico anterior tendo em vista os medicamentos, definidos como conteúdo do direito à saúde. Mas, além daquelas considerações, à operacionalização da AF são acrescidas peculiaridades, como se verá a seguir.

A Lei n. 8080/1990estabeleceu, no artigo $6^{\circ}$, inciso I, alínea $d$, a assistência terapêutica integral, inclusive farmacêutica, como atividade do campo de atuação

\footnotetext{
${ }^{17}$ AITH, Fernando. op. cit., p. 341; 343; 336.

${ }^{18}$ Reconhecidos na estrutura do SUS pela Lei n. 12.466, que alterou a Lei n. 8.080/1990. CANUT, Letícia. Exercício do direito coletivo à saúde na pós-modernidade jurídico-política brasileira: nova estrutura participativa para a formulação das políticas do Sistema Único, cit., p. 219.

${ }^{19}$ Sobre o tema do direito à saúde e o SUS como bens coletivos de titularidade de todos, ver: Id. Ibid.

${ }^{20}$ SANTOS, Lenir. A saga do direito à saúde: 28 anos de construção e desconstrução. Consultor Jurídico, 03 dez. 2016. Disponível em <http://www.conjur.com.br/2016-dez-03/lenir-santos-28-anos-construcaodesconstrucao-direito-saude>. Acesso em: 13 out. 2017.

${ }^{21}$ Nesse sentido, FOLY, Silvia Lane Freitas et al. Judicialização do acesso a medicamentos no Município de Itaperuna-RJ: perfil das demandas. Saúde \& Transf. Social, Florianópolis, v. 7, n. 2, p. 65, 2016. Disponível em: <http://incubadora.periodicos.ufsc.br/index.php/saudeetransformacao/article/view/4043/4548>. Acesso em: 13 out. 2017 e FLEURY, Sonia. Judicialização pode salvar o SUS. RevistaSaúde em Debate, Rio de Janeiro, v. 36, n. 93, p. 159, abr./jun. 2012. Disponível em: <https://www.almg.gov.br/export/ sites/default/acompanhe/eventos/hotsites/2015/ciclo_judicializacao_saude/documentos/material_ referencia/artigo_sonia_fleury.pdf $>$.

${ }^{22}$ O termo "assistência farmacêutica" será utilizado sob uma concepção ampla, de forma a abarcar as políticas do SUS que dispõem sobre medicamentos. Não se ocupará com questões conceituais.
} 
do SUS. Essa lei foi alterada posteriormente pela Lei n. $12.401 / 2011^{23}$,que definiu a "assistência terapêutica integral" no artigo 19-M como a oferta de procedimentos terapêuticos, inciso II, e a

I - dispensação de medicamentos e produtos de interesse para a saúde, cuja prescrição esteja em conformidade com as diretrizes terapêuticas definidas em protocolo clínico para a doença ou o agravo à saúde a ser tratado ou, na falta do protocolo, em conformidade com o disposto no art. 19-P. (Destaques nossos.)

De acordo com a Política Nacional de Medicamentos (PNM) ${ }^{24}$, a AF deve seguir a diretriz da descentralização da gestão conforme atividades sequenciais de: seleção, programação, aquisição, armazenamento e distribuição, controle da qualidade e utilização (esta última inclui a prescrição e a dispensação) dos medicamentos $^{25}$, havendo ainda a atividade de financiamento. Tais atividades devem se organizar de forma sistêmica ${ }^{26}$, formando um ciclo $^{27}$ no qual cada ente federativo pode assumir todas as atividades ao mesmo tempo ou apenas uma ou algumas delas. Portanto, se acrescem peculiaridades à já complexa operacionalização do SUS, já que é preciso identificar, em cada caso, qual ente federativo é responsável por determinada atividade. Antes de iniciado esse ciclo, há a fase de registro sanitário pela Agência Nacional de Vigilância Sanitária (Anvisa), sendo que este registro não significa a inclusão automática do medicamento nas listas do SUS ${ }^{28}$. A Política Nacional de Assistência Farmacêutica (PNAF), criada pela Resolução n. 338/2004 do Ministério da Saúde ${ }^{29}$ enfatizou a descentralização, com definição das responsabilidades das instâncias gestoras e a articulação entre elas (artigo 2º da Resolução n. 338/2004).

Eixo estratégico da PNAF é a adoção e atualização de uma Relação Nacional de Medicamentos Essenciais (Rename) no âmbito do SUS (artigo $2^{\circ}$, incisos IV,

\footnotetext{
${ }^{23}$ BRASIL. Lei 12.401, de 28 de abril de 2011 a. Altera a Lei no8.080, de 19 de setembro de 1990, para dispor sobre a assistência terapêutica e a incorporação de tecnologia em saúde no âmbito do Sistema Único de Saúde-SUS. Disponível em: <http://www.planalto.gov.br/CCIVIL_03/_Ato2011-2014/2011/Lei/ L12401.htm>. Acesso em: 13 out. 2017.

${ }^{24}$ MINISTÉRIO DA SAÚDE. Portaria 3.916, de 30 de outubro de 1998. Disponível em: <http://bvsms.saude. gov.br/bvs/saudelegis/gm/1998/prt3916_30_10_1998.html>. Acesso em: 13 out. 2017.

${ }^{25}$ PEPE, Vera Lúcia Edais et al. A judicialização da saúde e os novos desafios da gestão da assistência farmacêutica. Ciência \& Saúde Coletiva, v. 15, n. 5, p. 2405-2414, ago. 2010. Disponível em: <http://www. scielo.br/pdf/csc/v15n5/v15n5a15.pdf>. Acesso em: 13 out. 2017. http://dx.doi.org/10.1590/S141381232010000500015.

${ }^{26}$ MARÍN; OLIVEIRA apud PEPE, Vera Lúcia Edais et al. op. cit., p. 3; CHIEFFI, Ana Luiza; SIQUEIRA, Paula Facundo de. Judicialização da saúde no Estado de São Paulo. In: SANTOS, Lenir; TERRAZAS, Fernanda (Orgs.). Judicialização da saúde no Brasil. 1. ed. Campinas: Saberes Ed., 2014. p. 270.

${ }^{27}$ BRASIL. Conselho Nacional de Secretários de Saúde. Assistência Farmacêutica no SUS. Brasília: CONASS, 2011. (Coleção para entender a gestão do SUS, v. 7). Disponível em: <http://bvsms.saude.gov.br/bvs/ publicacoes/para_entender_gestao_sus_v.7.pdf>. Acesso em: 13 out. 2017.

${ }^{28}$ PEPE, Vera Lúcia Edais et al. op. cit.

${ }^{29}$ MINISTÉRIO DA SAÚDE. Resolução MS/CNS n. 338, de 06 de maio de 2004. Disponível em: <http://bvsms. saude.gov.br/bvs/saudelegis/cns/2004/res0338_06_05_2004.html> Acesso em: 13 out. 2017.
} 
III, VII, XIII, da Resolução n. 338/2004). De acordo com o artigo 25, do Decreto n. 7.508/2011, a Rename "compreende a seleção e a padronização de medicamentos indicados para atendimento de doenças ou de agravos no âmbito do SUS” e será “acompanhada do Formulário Terapêutico Nacional - FTN que subsidiará a prescrição, a dispensação e o uso dos seus medicamentos". Assim, como o FTN e os protocolos clínicos e diretrizes terapêuticas, a Rename deverá ser atualizada a cada dois anos, tarefa que cabe ao Ministério da Saúde (MS) com apoio da Comissão Nacional de Incorporação de Tecnologias (Conitec) ${ }^{30}$.

Para Luiza et al., a

Rename tem como finalidade, portanto, servir como eixo de organização das demais atividades do ciclo da assistência farmacêutica, subsidiando a definição das políticas de produção pública, aquisição e, consequentemente, da prescrição em todas as esferas de governo ${ }^{31}$.

Com base na Rename - elaborada conforme diretrizes pactuadas na CIT (artigo 26 do Decreto n. 7.508/2011)e perfil epidemiológico -,são formadas as relações de medicamentos essenciais estaduais (Resme) e municipais (Remume) e adotadas relações específicas e complementares de medicamentos pelos entes federativos ${ }^{32}$ -momento em que esses entes definem suas listas oficiais do SUS ${ }^{33}$,podendo, desde que justifiquem, ampliar a AF (artigo 28, parágrafo $1^{\circ}$, do Decreto n. 7.508/2011).

Compor ou não as listas oficiais do SUS leva à classificação dos medicamentos em padronizados e não padronizados ${ }^{34}$. A previsão em tais listas não significa a obrigatoriedade de seu fornecimento, já que, para acessar o tratamento, devem ser observados protocolos clínicos e diretrizes terapêuticas, de acordo com as previsões da Lei n. 8.080/1990 e do Decreto n. 7.508/2011 $1^{35}$, como mencionado.

${ }^{30}$ Criada com a inclusão do artigo 19-Q na Lei n. 8.080/1990. BRASIL. Lei 8.080, de 19 de setembro de 1990 , cit.

${ }^{31}$ LUIZA, Vera Lucia et al. O medicamento na política de saúde no Brasil: como os agentes comunitários de saúde podem contribuir para a promoção do acesso e do uso racional de medicamentos? In: MATTA, Gustavo Corrêa; PONTES, Ana Lúcia de Moura (Orgs.). Políticas de saúde: operacionalização do Sistema único de Saúde. Rio de Janeiro: EPSJV; Fiocruz, 2007. p. 238.

${ }^{32}$ De acordo com o artigo 27, do Decreto n. 7.508/2011: "Respeitadas as responsabilidades dos entes pelo financiamento de medicamentos, de acordo com o pactuado nas Comissões Intergestores". BRASIL. Decreto 7.508, de 28 de junho de 2011, cit.

${ }^{33}$ BRASIL. Conselho Nacional de Secretários de Saúde Assistência Farmacêutica no SUS. cit, p. 26

${ }^{34}$ BORGES, Daniela da Costa Leite; UGÁ, Maria Alicia Dominguez. Conflitos e impasses da judicialização na obtenção de medicamentos: as decisões de 1a instância nas ações individuais contra o Estado do Rio de Janeiro, Brasil, em 2005. Caderno de Saúde Pública, Rio de Janeiro, v. 26, n. 1, p. 62, jan. 2010. Disponível em: <http://www.scielosp.org/pdf/csp/v26n1/07.pdf>. Acesso em: 13 out. 2017. http://dx.doi. org/10.1590/S0102-311X2010000100007.

${ }^{35}$ WANG, Daniel Wei L. et al. Os impactos da judicialização da saúde no município de São Paulo: gasto público e organização federativa. Revista de Administração Pública, Rio de Janeiro, v. 48, n. 5, p. 1201, set./out. 2014. Disponível em: <http://www.scielo.br/pdf/rap/v48n5/06.pdf>. http://dx.doi.org/10.1590/003476121666. 
A Rename 2012, atualizada pela Rename $2014^{36}$ com atenção à descentralização e às pactuações intergestores, dispõe em seu artigo $1^{\circ}$ sobre a estruturação do elenco de medicamentos e insumos conforme segue:

I - Relação Nacional de Medicamentos do Componente Básico da Assistência Farmacêutica;

II - Relação Nacional de Medicamentos do Componente Estratégico da Assistência Farmacêutica;

III - Relação Nacional de Medicamentos do Componente Especializado da Assistência Farmacêutica;

IV - Relação Nacional de Insumos; e

V - Relação Nacional de Medicamentos de Uso Hospitalar.

$\$ 1^{\circ}$ Incluem-se entre os medicamentos que compõem a RENAME os que forem definidos no âmbito da Política Nacional de Atenção Integral em Genética Clínica. (Destaques nossos.)

Na Portaria MS/GM n. 399/2006 37 , os componentes dos incisos I, II e III já constavam como aqueles da organização do bloco de financiamento da AF do SUS, tendo sido mantidos pela Portaria MS/GM n. 204/2007 ${ }^{38}$, que regulou o financiamento e as transferências de recursos (artigo 24),com destaque para a qualificação da descentralização com base na pactuação intergestores. Esta portaria sofreu diversas modificações, tendo sido alterada, inclusive, a denominação "Componente Medicamentos de Dispensação Excepcional" para "Componente especializado da Assistência Farmacêutica"39.

A Portaria MS/GM n. 1.554/2013explica que o componente especializado visa ao atendimento integral do tratamento por meio de medicamentos, em nível ambulatorial, “cujas linhas de cuidado estão definidas em Protocolos Clínicos e Diretrizes Terapêuticas publicadas pelo Ministério da Saúde” e define as responsabilidades/competências dos entes federativos de acordo com grupos de medicamentos

\footnotetext{
${ }^{36}$ BRASIL. Ministério da Saúde. Secretaria de Ciência, Tecnologia e Insumos Estratégicos. Departamento de Assistência Farmacêutica e Insumos Estratégicos. Relação Nacional de Medicamentos Essenciais: RENAME 2014. 9. ed. - Brasília: Ministério da Saúde, 2015. Disponível em: <http://conitec.gov.br/images/ Artigos_Publicacoes/Rename/Rename-2014-Julho2015.pdf>. Acesso em: 13 out. 2017.

${ }^{37}$ MINISTÉRIO DA SAÚDE. Portaria MS/GM 399, de 22 de fevereiro de 2006. Divulga o Pacto pela Saúde 2006 - Consolidação do SUS e aprova as Diretrizes Operacionais do Referido Pacto. Disponível em: <http:// bvsms.saude.gov.br/bvs/saudelegis/gm/2006/prt0399_22_02_2006.html>. Acesso em: 13 out. 2017.

${ }^{38}$ MINISTÉRIO DA SAÚDE. Portaria MS/GM 204, de 29 de janeiro de 2007. Regulamenta o financiamento e a transferência dos recursos federais para as ações e os serviços de saúde, na forma de blocos de financiamento, com o respectivo monitoramento e controle. Disponivel em: <http://bvsms.saude.gov.br/ bvs/saudelegis/gm/2007/prt0204_29_01_2007.html>. Acesso em: 13 out. 2017.

${ }^{39}$ Alteração feita pela Portaria n. 2.981/2009, já revogada pela Portaria MS/GM n. 1.554/2013. MINISTÉRIO DA SAÚDE. Portaria MS/GM 1554, de 30 de julho de 2013. Dispõe sobre as regras de financiamento e execução do Componente Especializado da Assistência Farmacêutica no âmbito do Sistema Único de Saúde (SUS). Disponível em: <http://bvsms.saude.gov.br/bvs/saudelegis/gm/2013/prt1554_30_07_2013. html>. Acesso em: 13 out. 2017.
} 
G1, G2 e G3 ${ }^{40}$, estabelecendo a qual ente federativo cabe cada uma das atividades - financiamento, aquisição, programação etc.

O Componente Estratégico da AF continua previsto no artigo 26 da Portaria MS/GM n. 204/2007 para:

I - controle de endemias, tais como a tuberculose, a hanseníase, a malária, a leishmaniose, a doença de Chagas e outras doenças endêmicas de abrangência nacional ou regional;

II - antirretrovirais do programa DST/Aids;

III - sangue e hemoderivados; e

IV - imunobiológicos ${ }^{41}$.

Apesar de cada programa ter suas especificidades, o MS clarifica em seu site a competência de cada ente federativo em relação a esses medicamentos ${ }^{42}$.

O Componente Básico da AF, que passou a ser regulamentado pela Portaria MS/GM n. 1.555/2013 ${ }^{43}$, destina-se "à aquisição de medicamentos e insumos, incluindo-se aqueles relacionados a agravos e programas de saúde específicos, no âmbito da Atenção Básica à Saúde" (artigo $2^{\circ}$ ). A portaria estabelece regras de competência dos entes federativos para seleção, financiamento, aquisição, armazenamento e distribuição desses medicamentos e fortalece o papel das comissões intergestores na definição de competências (artigos $3^{\circ}$, e $5^{\circ}$ ao 14 , da Portaria n. 1.555/2013).

Toda essa organização deve atender à promoção do uso racional e seguro de medicamentos, diretriz da PNM e da PNAF que é reforçada pela Rename.

Além disso, a compra de medicamentos pelo Estado deve respeitar a Lei n. 8.666/1993 ${ }^{44}$ - sobre licitações e contratos administrativos - e “a regulamentação contida nas Resoluções da Câmara de Regulação do Mercado de Medicamentos (CMED)”45.

\footnotetext{
${ }^{40}$ Artigos $2^{\circ}$ e $3^{\circ}$ da Portaria 1.554/2013, que teve o Grupo 1B alterado pela Portaria MS/GM 1.996/2013. MINISTÉRIO DA SAÚDE. Portaria MS/GM 1554, de 30 de julho de 2013, cit.

${ }^{41}$ No site do Ministério da Saúde constam, dentre os programas estratégicos, além dos ora citados: Alimentação e Nutrição; Controle do Tabagismo; Influenza; Saúde da Criança. APRESENTAÇÃO. Portal da Saúde. Disponível em: <http://portalsaude.saude.gov.br/index.php/o-ministerio/principal/leia-mais-oministerio/1132-sctie-raiz/daf-raiz/cgafme/I1-cgafme/11722-apresentacao>.

${ }^{42} \mathrm{Em}$ sua página eletrônica, o Ministério da Saúde dispõe sobre financiamento e aquisição centralizados; elaboração de protocolos de tratamento; planejamento e programação e distribuição aos estados e municípios. Aos estados cabe: o armazenamento; a distribuição às regionais ou municípios e a programação. Ficando os municípios responsáveis pelo armazenamento; distribuição às Unidades de saúde, programação e dispensação Vide: APRESENTAÇÃO. Portal da Saúde, cit.

${ }^{43}$ MINISTÉRIO DA SAÚDE. Portaria MS/GM 1.555, de 30 de julho de 2013. Dispõe sobre as normas de financiamento e de execução do Componente Básico da Assistência Farmacêutica no âmbito do Sistema Único de Saúde (SUS). Disponível em: <http://bvsms.saude.gov.br/bvs/saudelegis/gm/2013/ prt1555_30_07_2013.html>.Acesso em jan. 2017.

${ }^{44}$ BRASIL. Lei n. 8666, de 21 de junho de 2013. Regulamenta o art. 37, inciso XXI, da Constituição Federal, institui normas para licitações e contratos da Administração Pública e dá outras providências. Disponível em: <http://www.planalto.gov.br/ccivil_03/leis/L8666compilado.htm>. Acesso em: 13 out. 2017.

${ }^{45}$ BRASIL. Conselho Nacional de Secretários de Saúde Assistência Farmacêutica no SUS. cit., p. 28.
} 
$\mathrm{O}$ acesso e a distribuição de medicamentos na rede deve observar essa sistemática de operacionalização da AF do SUS, que "deveria estar contemplada nos Planos de Saúde ou nos Planos de Assistência Farmacêutica (portanto, definidos juntamente com os Conselhos de Saúde) para informação fácil dos profissionais de saúde e da população"46.

Sem pretensão de esgotar ou detalhar o assunto, traçou-se uma visão geral sobre operacionalização da AF no SUS para evidenciar que o termo "medicamentos" assume diferentes qualificações e especificações, por exemplo: padronizado ou não padronizado (se padronizado, ainda é classificado como componente básico, estratégico, especializado, hospitalar, oncológico); experimental; se tem ou não registro na Anvisa etc. Além disso, a depender da qualificação que recebe, serão seguidas regras próprias, inclusive sobre as competências dos entes federativos - que são estabelecidas tendo em vista o ciclo da assistência farmacêutica. Trata-se de uma sistemática de operacionalização extremamente complexa, difícil de ser compreendida, conhecida e, por vezes, de difícil execução.

\section{A operacionalização da assistência farmacêutica do SUS no Município de São José (SC)}

Os estados e municípios devem organizar e operacionalizar suas políticas de assistência farmacêutica conforme a sistemática acima apresentada. Como visto, aquele quadro pode ser configurado por políticas estabelecidas no âmbito estadual, regional e municipal, o que dá relevo aos instrumentos normativos emitidos nesses três níveis, devendo haver atenção às pactuações feitas nas comissões intergestores estaduais (CIB) e regionais (CIR) acerca da AF. Procurar-se-á expor algumas particularidades da operacionalização da AF no Município de São José. Vale destacar que os dados examinados, em sua quase totalidade, foram obtidos por meio de pesquisa em sites oficiais do município, do Estado de Santa Catarina e do TJSC.

De acordo com a deliberação n. 457/2012 $2^{47}$ da CIB do Estado de SC, o município estudado integra, ao lado de outros 21 municípios, a região de saúde da Grande Florianópolis, que compõe a macrorregião de saúde da Grande Florianópolis- aprovada pela Deliberação n. 458/2012 ${ }^{48}$ da CIB -, com uma população de referência de 1.041.828 habitantes. Por previsão na Deliberação n. 457/2012 da CIB, foi criada a CIR da Grande Florianópolis, com regimento interno aprovado em 2015, o que possibilitou a regulamentação da AF da região por meio desse foro.

\footnotetext{
${ }^{46}$ LUIZA, Vera Lucia et al. op. cit., p. 240.

${ }^{47}$ SECRETARIA DE ESTADO DA SAÚDE DE SANTA CATARINA. Deliberação 457/CIB/12, de 8 de novembro, de 2012. Disponivel em: <http://portalses.saude.sc.gov.br/index.php?option=com_docman\&task=cat_view \&gid=747\&ltemid=128\&limitstart=50>. Acesso em: 13 out. 2017.

${ }^{48}$ Id. Ibid.
} 
No Plano Municipal de Saúde (2014-2017) ${ }^{49}$, ao lado de quatro diretorias que compõem a estrutura da Secretaria Municipal de Saúde, encontram-se a Diretoria de Assistência Farmacêutica e o Núcleo Técnico de Ações Judiciais (Nutaj) ${ }^{50}$ - criado pelo Decreto n. 31.019/2009 e subordinado ao gabinete do secretário municipal de Saúde ${ }^{51}$-, com atuação no controle e avaliação das ações judiciais de fornecimento de medicamentos, auxiliando a Procuradoria Geral do Município nas defesas referentes a tais ações e fornecendo informações de sua competência para órgãos públicos, tendo como funções:

- Receber as ações judiciais;

- Encaminhar para fornecimento quando medicamento em estoque, almoxarifado ou para aquisição realizada pelo setor de compras desta Secretaria;

- Responder às solicitações de medicamentos não padronizados ou fora das exigências da padronização;

- Pactuar quando determinada nas decisões judiciais a responsabilidade de mais de um ente (Município/Estado/União);

- Atualizar e alimentar um banco de dados com todos os medicamentos solicitados e pacientes beneficiados para que os Procuradores do Município possam ter fundamentação quando da defesa junto ao Poder Judiciário.

Também vem propondo diretrizes [...], tudo submetido ao melhor juízo da Administração, que age sempre em defesa do interesse público ${ }^{52}$.

O plano de saúde dispõe de forma abrangente sobre a AF no município, sem mencionar as normas voltadas a regulamentar o tema, que não especificam as atividades do ciclo da AF (que são de competência do município) e não esclarecem se há um plano municipal de assistência farmacêutica. Dispõe apenas que:

Atualmente a Secretaria de Saúde disponibiliza gratuitamente em torno de: 180 medicamentos nas Farmácias Básicas (incluindo, além dos medicamentos básicos, os medicamentos de controle especial, insulinas, medicamentos do Programa do Tabagismo e Saúde da Mulher); cerca de 130 medicamentos de alto custo na Farmácia Especializada - CEAF; 100 itens na Farmácia Estratégica do CTA/DST; além dos 115 medicamentos disponibilizados

\footnotetext{
${ }^{49}$ MUNICÍPIO DE SÃO JOSÉ-SC. Plano Municipal de Saúde 2014/2017. 2013. Disponível em: <http://doczz. com.br/doc/240178/plano-municipal-de-sa\%C3\%BAde-2014-2017>. Acesso em: 11 dez. 2017.

${ }^{50}$ RIBEIRO, J. S. et al. Judicialização da Saúde: direitos coletivos versus direitos individuais. In: PEREIRA, M. F. et al. (Org.). Contribuições para a gestão do SUS. Florianópolis: Fundação Boiteux, 2013. p. 117. (Coleção Gestão da Saúde Pública, v. 4).

${ }^{51}$ A estruturação completa no SUS no município pode ser observada no Plano de Saúde 2014-2017. MUNICÍPIO DE SÃO JOSÉ-SC. op. cit. p.45-46.

${ }^{52}$ Id. Ibid. p. 48
} 
gratuitamente ou comercializados a preço de custo pelo Programa da Farmácia Popular do Brasil.[... ${ }^{53}$.

A Remume não foi localizada nos sites oficiais da prefeitura nem da secretaria de saúde. Acessou-se a Remume2014 por meio de contato com a coordenadora do Nutaj. Essa relação, no entanto, não identifica como foi feita a seleção de medicamentos (se municipal ou se por pactuação intergestores) e não faz referência às atividades do ciclo da AF.

Foi possível identificar no site da Corregedoria Geral de Justiça do TJSC a Pactuação n. 192/CIB/11 ${ }^{54}$ que aprova as normas de execução e de financiamento da AF na atenção básica e uma lista de medicamentos de competência dos municípios. Nesse instrumento, há definição de competências/responsabilidades para os municípios em relação às atividades de financiamento e aquisição e, ainda, a previsão para inclusão de medicamentos específicos nas Remumes.

No site da secretaria de estado da saúde, na página sobre o Componente Básico da Assistência Farmacêutica, identificou-se a Deliberação n. 501/CIB/13 ${ }^{55}$ que estipula regras de competência para os municípios em relação a diferentes atividades do ciclo da $\mathrm{AF}^{56}$ - envolvendo desde a seleção e o financiamento até a distribuição do medicamento. Já na página sobre o Componente Especializado da Assistência Farmacêutica, foi acessada a Deliberação n. 398/CIB/14 ${ }^{57}$, que também chega a estipular a responsabilidade dos municípios, especialmente em relação à atividade de estoque.

Nessa breve apresentação, observa-se que a complexidade e as dificuldades mencionadas ao final do tópico anterior podem se agravar no âmbito municipal. Isso porque, nesse nível, tornam-se mais difíceis o acesso e o conhecimento de todas as normas e ações que sistematizam a operacionalização da AF. Portanto, essa realidade um fator que favorece o desconhecimento do SUS pelos operadores do direito ${ }^{58}$.

${ }^{53} \mathrm{~A}$ estruturação completa no SUS no município pode ser observada no Plano de Saúde 2014-2017. MUNICÍPIO DE SÃO JOSÉ-SC. op. cit. p. 75.

${ }^{54}$ SECRETARIA DE ESTADO DA SAÚDE DE SANTA CATARINA. Deliberação 192/CIB/2011 de 27 de julho de 2011. Disponivel em: <http://portalses.saude.sc.gov.br/index.php?option=com_docman\&task=cat_ view\&gid=630\&ltemid=128>. Acesso em: 13 out. 2017.

${ }^{55}$ Editada considerando as Portarias n. $1.554 \mathrm{GM} / \mathrm{MS}$ e n. $1.555 \mathrm{GM} / \mathrm{MS}$, ambas de 2013. SECRETARIA DE ESTADO DA SAÚDE DE SANTA CATARINA. Deliberação 501/CIB/2013, de 27 de novembro de 2013. Disponível em: <http://portalses.saude.sc.gov.br/index.php?option=com_content\&view=article\&id=468\% 3Aassistencia-farmaceutica-basica\&catid=501\&ltemid=210>. Acesso em: 13 out. 2017.

${ }^{56}$ Sobre a temática vide: DRESCH, Renato Luís. Federalismo solidário: a responsabilidade dos entes federativos na área da saúde. In: SANTOS, Lenir; TERRAZAS, Fernanda (Orgs.) Judicialização da saúde no Brasil. 1. ed. Campinas: Saberes Ed., 2014. p.30; 32-35; 46-51.

${ }^{57}$ SECRETARIA DE ESTADO DA SAÚDE DE SANTA CATARINA. Deliberação 398/CIB/14, de 25 de setembro de 2014. Disponível em: <CATARINA.http://portalses.saude.sc.gov.br/index.php?option=com_content\&vi ew=article\&id=470\%3Amedicamentos-excepcionais-\&catid=505\&ltemid=210 >. Acesso em: 13 out. 2017. ${ }^{58}$ Esse desconhecimento foi apontado no relatório final, de 2014, do grupo de trabalho vinculado à CIT. SANTOS, Lenir; CARVALHO, André Luis Bonifácio. O impacto da judicialização sob a ótica da Comissão Intergestores Tripartite. 2014. In: SANTOS, Lenir; TERRAZAS, Fernanda (Orgs.) Judicialização da saúde no Brasil. 1. ed. Campinas: Saberes Ed., 2014. p. 256. 


\section{Efeitos da judicialização sobre a operacionalização do SUS e de sua Assistência Farmacêutica}

Outro fenômeno jurídico a se destacar, diante da força normativa das normas constitucionais e da aplicação imediata do direito à saúde, é a judicialização. Ela pode envolver a exigibilidade judicial de prestações de saúde: derivadas-aquelas cujo conteúdo e cujas competências já estão definidos em políticas públicas - e originárias $^{59}$ - que ainda não estão previstas em políticas, sendo requeridas a partir de previsões genéricas da $\mathrm{CF} / 88^{60}$. $\mathrm{Na} \mathrm{AF}$, as prestações derivadas se identificam com medicamentos padronizados e as originárias, com aqueles não padronizados.

A “judicialização” vem sendo compreendida sob diferentes olhares, estando claro que ela apresenta aspectos positivos $^{61}$ e negativos para a concretização do direito à saúde $\mathrm{e}^{62,63,64,65}$. O termo será utilizado aqui no sentido de intensa atuação do Poder Judiciário, não se ocupando com questões terminológicas ou descritivas. Serão sistematizados alguns efeitos positivos e negativos da judicialização que se refletem na operacionalização geral do SUS e, em alguns casos, nas peculiaridades da operacionalização de sua AF. Por questões metodológicas, tais efeitos serão divididos em tópicos, apesar de estarem estritamente conectados.

Como efeito positivo pode ser citada a possibilidade de corrigir debilidades provenientes do Legislativo e do Executivo ${ }^{66}$, identificadas como falhas ${ }^{67}$ imputadas: à gestão/gerenciamento da $\mathrm{AF}^{68}$; à dificuldade de acesso às listas oficiais de medicamentos ${ }^{69}$; ao processo de incorporação de novos medicamentos às listas vigentes ${ }^{70,71}$ - que envolve a solicitação de prestações originárias de medicamentos, podendo também envolvero

\footnotetext{
${ }^{59}$ CANOTILHO, J. J. Gomes. Direito Constitucional e teoria da Constituição. 7. ed. 6. reimp. Coimbra: Almedina, 2003. p. 477.

${ }^{60}$ SARLET, Ingo Wolfgang. op. cit., p. 154.

${ }^{61}$ Interessante avaliação de Fleury e Fleury e Faria sobre o efeito positivo da judicialização quando se trata de controlar a participação de entidades privadas no SUS. Oportunidade em que chegam a mencionar "seja bem-vinda a judicialização". FLEURY, Sonia. Judicialização pode salvar o SUS, cit., p. 159-162.

${ }^{62}$ GEBRAN NETO, João Pedro. Direito constitucional à saúde e suas molduras jurídicas. In: SCHULZE, Clenio Jair; GEBRAN NETO, João Pedro. Direito à saúde. Análise à luz da judicialização. Porto Alegre: Verbo Jurídico, 2015. p.154-158.

${ }^{63}$ FLEURY, Sonia; FARIA, Mariana. A judicialização como ameaça e salvaguarda do SUS. In: SANTOS, Lenir; TERRAZAS, Fernanda (Orgs.) Judicialização da saúde no Brasil. 1. ed. Campinas: Saberes Ed., 2014. p. 121.

${ }^{64}$ OLIVEIRA, Luciana da Veiga. Comitês Executivos da Saúde. In: SANTOS, Lenir; TERRAZAS, Fernanda (Orgs.) Judicialização da saúde no Brasil. 1. ed. Campinas: Saberes Ed., 2014. p. 190-191.

${ }^{65} \mathrm{CHIEFFI}$, Ana Luiza; SIQUEIRA, Paula Facundo de. op. cit., p. 297-300.

${ }^{66}$ FLEURY, Sonia. Judicialização pode salvar o SUS, cit., p. 159.

${ }^{67}$ Ib. Ibid. p.159 e FOLY, Silvia Lane Freitas et al. op. cit., p.58; 63.

${ }^{68}$ PEPE, Vera Lúcia Edais et al. op. cit., p. 6.

${ }^{69}$ MACHADO, Marina Amaral de Ávila. Judicialização do acesso a medicamentos no Estado de Minas Gerais, Brasil. Revista Saúde Pública, v. 45, n. 3, p. 590-598, jun. 2011. Disponível em: <http://www.scielo.br/ scielo.php?script=sci_arttext\&pid=S0034-89102011000300018>. $\quad$ http://dx.doi.org/10.1590/S003489102011005000015.

${ }^{70} \mathrm{FOLY}$, Silvia Lane Freitas et al. op. cit., p. 66.

${ }^{71}$ SCHULZE, Clenio Jair; GEBRAN NETO, João Pedro. Direito à saúde. Análise à luz da Judicialização, cit., p. 49.
} 
papel da Anvisa caso o medicamento ainda não tenha registro no país -; a atualização das indicações terapêuticas constantes do registro do medicamento - que envolve atualização de protocolos clínicos e a prescrição e o uso offlabel, ou seja, diferente daquela prevista nas indicações -; às omissões do Executivo em garantir prestações da assistência farmacêutica já definidas nas políticas públicas ${ }^{72}$, contexto em que se reconhece a legitimidade da ação judicial na garantia desse direito fundamental ${ }^{73}$. Sob esta última perspectiva, a judicialização somente será positiva para o SUS se o Judiciário atuar conforme a sistemática de operacionalização do sistema, fazendo com que o SUS funcione como SUS, ou seja, considerando seus princípios, diretrizes, o conteúdo e as competências definidas. Caso contrário, essa atuação assumirá caráter negativo ${ }^{74}$.

Outro efeito positivo é aquele indutor de políticas públicas ${ }^{75}$, "não só alterando as políticas públicas já em curso, mas indicando como devem ser pensadas as políticas para o futuro[... $]^{76 "}$. Aqui se destacamos pedidos de prestações originárias e seu potencial de induzir a criação de novas políticas, como foi o caso dos medicamentos para HIV/Aids. Para alguns autores, a Lei n. 12.401/2011, ao revisar a Lei n. $8.080 / 1990^{77}$, representa esse efeito positivo. No entanto, caso a indução venha de pressão da indústria farmacêutica, esse critério poderá assumir feição negativa.

Os efeitos negativos da judicialização sobre a operacionalização do SUS e da sua AF, de uma forma geral, derivam ou estão conectados ao fato de o Judiciário não considerar as políticas públicas em suas decisões ${ }^{78}$. Tal desconsideração é constatada diante de decisões com fundamentos jurídicos pautados apenas na $\mathrm{CF}^{79,80,81,82}$,

\footnotetext{
${ }^{72}$ BORGES, Daniela da Costa Leite; UGÁ, Maria Alicia Dominguez. op. cit., p. 66-67.
}

${ }^{73}$ MACHADO, Marina Amaral de Ávila. op. cit., p. 597; FOLY, Silvia Lane Freitaset al. op. cit., p. 58; 66; PEPE, Vera Lúcia Edais et al. op. cit., p. 2-3; SCHULZE, Clenio Jair; GEBRAN NETO, João Pedro. Direito à saúde. Análise à luz da Judicialização, cit., p. 103; 79.

${ }^{74}$ Nesse sentido, especialmente no que diz respeito à atribuição de competências dos entes federativos, Dresch e Freitas tecem considerações sobre a atuação do Judiciário em conformidade com a organização do SUS. FREITAS, Cristina Leitão Teixeira de. Judicialização da saúde. Solidariedade e ressarcimento: destaques da posição dos estados frente à polarização de entendimentos. In: SANTOS, Lenir; TERRAZAS, Fernanda (Orgs.) Judicialização da saúde no Brasil. 1. ed. Campinas: Saberes Ed., 2014. p. 59-96 e DRESCH, Renato Luís. op. cit., p. 25-57.

${ }^{75}$ Há autores que destacam o papel tanto de fomento como de revisão das políticas. Id. Ibid., p. 155.

${ }^{76}$ BORGES, Daniela da Costa Leite; UGÁ, Maria Alicia Dominguez. op. cit., p. 67.

${ }^{77}$ SCHULZE, Clenio Jair; GEBRAN NETO, João Pedro. Direito à saúde. Análise à luz da judicialização, cit., p. 155-156.

${ }^{78}$ SANTOS, Lenir; CARVALHO, André Luis Bonifácio. O impacto da judicialização sob a ótica da Comissão Intergestores Tripartite, cit., p. 257.

${ }^{79}$ SCHULZE, Clenio Jair; GEBRAN NETO, João Pedro. Direito à saúde. Análise à luz da judicialização, cit., p. 122; 158; 159.

${ }^{80}$ ASENSI, Felipe. Responsabilidade solidária dos entes da Federação e "efeitos colaterais" no direito à saúde. Revista Direito Sanitário, São Paulo, v. 16, n. 3, p. 154, jun. 2016. Disponível em: <https://www. revistas.usp.br/rdisan/article/download/111658/109689>. Acesso em: 13 out. 2017. http://dx.doi. org/10.11606/issn.2316-9044.v16i3p145-156.

${ }^{81}$ SCHULZE, Jair Clenio. Direito à saúde - novas perspectivas. In: SANTOS, Lenir; TERRAZAS, Fernanda (Orgs.) Judicialização da saúde no Brasil. 1. ed. Campinas: Saberes Ed., 2014. p. 167.

${ }^{82}$ BORGES, Daniela da Costa Leite; UGÁ, Maria Alicia Dominguez. op. cit. 
por vezes na Constituição estadual e na Lei n. 8.080/1990, e que não se dedicam à análise do caso clínico do autor da ação ${ }^{83}$.

A atuação judicial nesse caminho é prejudicial à operacionalidade do SUS, colabora para a sua desorganização ${ }^{84,85,86}$ e de sua AF e desestrutura toda a complexa sistemática apresentada nos tópicos I, II e III, afetando, por exemplo, a descentralização da $\mathrm{AF}^{87}$, diretriz que, além de contar a participação da comunidade, está voltada para a concretização dos princípios da universalidade e da integralidade, tendo em vista a estipulação de competências específicas para os entes federativos de acordo com cada atividade do ciclo da assistência farmacêutica ${ }^{88}$, em um processo em que as negociações e pactuações intergestores possuem papel fundamental. Para observar essa prejudicialidade de forma mais esmiuçada, serão apontados a seguir alguns efeitos negativos da judicialização para a operacionalização do SUS e de sua AF.

Como efeito negativo, cita-se a concessão de medicamentos que não constam nas listas oficiais ${ }^{89}$ com fundamentação principal baseada na prescrição médica ${ }^{90,91}$, sem observar critérios de uso racional, segurança e evidência científica ${ }^{92,93}$. Isso envolve temas como: a dispensação de medicamentos não padronizados; o uso off label; a rejeição da alternativa terapêutica existente no SUS $^{94}$ sem fundamentação científica ou da medicina baseada em evidência; o desrespeito das diretrizes da PNM e da PNAF de uso racional e seguro do medicamento; o desrespeito aos protocolos clínicos e ao papel da Anvisa no registro de medicamentos; às disposições da Lei n.

${ }^{83}$ SCHULZE, Jair Clenio. Direito à saúde - novas perspectivas, cit., p. 175; 177; 179. SCHULZE, Clenio Jair; GEBRAN NETO, João Pedro. Direito à saúde. Análise à luz da judicialização, cit., p. 67-68.

${ }^{84}$ LEITE, Silvana Nair et al. Ações Judiciais e demandas administrativas na garantia do direito de acesso a medicamentos em Florianópolis. Revista de Direito Sanitário, São Paulo. v. 10, n. 2, p. 16, jul./out. 2009. Disponível em: <http://www.revistas.usp.br/rdisan/article/view/13161>. http://dx.doi.org/10.11606/ issn.2316-9044.v10i2p13-28.

${ }^{85}$ SCHULZE, Clenio Jair; GEBRAN NETO, João Pedro. Direito à saúde. Análise à luz da judicialização, cit., p. $107 ; 111 ; 154$.

${ }^{86}$ SANTOS, Lenir. Judicialização da saúde e a incompreensão do SUS.In: SANTOS, Lenir; TERRAZAS, Fernanda (Orgs.) Judicialização da saúde no Brasil. 1. ed. Campinas: Saberes Ed., 2014. p.128; 156; OLIVEIRA, Luciana da Veiga. op. cit., p. 193; ASENSI, Felipe. op. cit., p. 155; FREITAS, Cristina Leitão Teixeira de. op. cit., p. 93-96.

${ }^{87}$ BORGES, Daniela da Costa Leite; UGÁ, Maria Alicia Dominguez. op. cit., p. 61-62; BRASIL. Advocacia Geral da União. Consultoria Jurídica/Ministério da Saúde. Intervenção Judicial na saúde pública. Panorama no âmbito da Justiça Federal e Apontamentos na seara das Justiças Estaduais. 2013. Disponível em: <http://u.saude.gov.br/images/pdf/2014/maio/29/Panorama-da-judicializa----o---2012---modificado-emjunho-de-2013.pdf>. Acesso em: 13 out. 2017.

${ }^{88}$ PEPE, Vera Lúcia Edais et al. op. cit., p.1; CHIEFFI, Ana Luiza; SIQUEIRA, Paula Facundo de. op. cit., p. $270-271$. ${ }^{89} \mathrm{SCHULZE}$, Clenio Jair; GEBRAN NETO, João Pedro. Direito à saúde. Análise à luz da judicialização, cit., p. 96. ${ }^{90}$ PEPE, Vera Lúcia Edais et al. op. cit., p. 4-5.

${ }^{91}$ SANTOS, Lenir. Judicialização da saúde e a incompreensão do SUS, cit., p. 156.

${ }^{9}$ BORGES, Daniela da Costa Leite; UGÁ, Maria Alicia Dominguez. op. cit., p. 66.

${ }_{93}^{3}$ SANTOS, Lenir. Judicialização da saúde e a incompreensão do SUS, cit., p. 159.

${ }^{94}$ Gebran Neto destaca ser "necessária a realização de laudo médico (ou perícia, sendo aquele preferível) indicando a necessidade do tratamento excepcional, seus efeitos, estudos da Medicina baseada em Evidências (MBE) e vantagens para o paciente, além de comparar com eventuais fármacos fornecidos pelos SUS." SCHULZE, Clenio Jair; GEBRAN NETO, João Pedro. Direito à saúde. Análise à luz da judicialização, cit., p. 187. 
12.401/2011 e, consequentemente, às recomendações da Conitec ${ }^{95}$. Esse efeito pode, inclusive, gerar graves consequências para o próprio paciente.

Outro grande efeito negativo, especialmente para a operacionalização da $\mathrm{AF}$ é a interpretação judicial da competência comum do artigo 23, inciso II, da CF/88 como responsabilidade solidária dos entes federativos ${ }^{96,97}$, permitindo a propositura da ação contra um, alguns ou todos os entes federativos conjuntamente ou não, conforme a opção do interessado e independentemente do tipo de prestação ou medicamento requerido. Cuida-se de posicionamento consolidado nos tribunais superiores (Supremo Tribunal Federal - STF - e Superior Tribunal de Justiça - STJ) - tema da Proposta de Súmula Vinculante n. $4^{98,99}$ e da recente decisão do primeiro Incidente de Resolução de Demandas Repetitivas (IRDR) instaurado pelo TJSC ${ }^{100}$.

Apesar de consolidada em tais tribunais, essa interpretação é feita fora do contexto de institucionalidade constitucional do SUS ${ }^{101}$, desrespeita os princípios e diretrizes do sistema e interpreta o princípio da integralidade ${ }^{102,103,104}$ de forma desconexa com as diretrizes de descentralização, hierarquização e regionalização, não se identificando com a explicada solidariedade no âmbito do sistema, que depende de pactuações intergestores. Como dito, a solidariedade e a integralidade devem existir na rede, e não no âmbito de cada ente federativo de forma isolada ${ }^{105}$. Essa interpretação do Judiciário vem configurar uma "responsabilidade preguiçosa"106.

Disso resulta outro efeito negativo: a responsabilização dos municípios para fornecerem medicamentos que não são de sua competência ${ }^{107}$, gerando sobrecarga para esse ente federativo, seja por se tratar de medicamentos padronizados previstos como responsabilidade de outro ente federativo - por exemplo, e em regra, os medicamentos

\footnotetext{
${ }^{95}$ PEPE, Vera Lúcia Edais et al. op. cit., p. 3-5.

${ }^{96}$ ASENSI, Felipe. op. cit., p. 145-156, p 149; DRESCH, Renato Luís. op. cit., p. 28; FREITAS, Cristina Leitão Teixeira de. op. cit., p.59-96.

${ }^{97}$ Lenir Santos destaca o papel das pactuações intergestores nesse cenário. SANTOS, Lenir. Judicialização da saúde e a incompreensão do SUS, cit., p. 144-148.

${ }^{98}$ Ainda em trâmite no STF, a proposta foi sobrestada até o julgamento de mérito do RE 566.471. Disponível em: <http://www.stf.jus.br/portal/cms/verNoticiaDetalhe.asp?idConteudo=303868>. Acesso em: 13 out. 2017. ${ }^{99}$ WANG, Daniel Wei L. et al. op. cit., p. 1194, 1195.

100IRDR 0302355-11.2014.8.24.0054/50000, de Rio do Sul. Decido em $1^{\circ}$ de dezembro de 2016, tendo tido por objeto Disponível em: <http://busca.tjsc.jus.br/jurisprudencia/html.do?q=irdr\&only_ementa=\&fra se=\&id=AABAg7AADAAloLwAAB\&categoria=acordao_5>. Acesso e: 13 out. 2017.

${ }^{101}$ FLEURY, Sonia; FARIA, Mariana. op. cit., p. 145; DRESCH, Renato Luís. op. cit., p.33; WANG, Daniel Wei L. et al. op. cit., p. 1202, 1203.

102SANTOS, Lenir. Judicialização da saúde e a incompreensão do SUS, cit., p. 133-144.

${ }^{103}$ Sobre os princípios da universalidade e da integralidade frente à judicialização vide: FLEURY, Sonia; FARIA, Mariana. op. cit., p. 114-115.

${ }^{104}$ SCHULZE, Clenio Jair; GEBRAN NETO, João Pedro. Direito à saúde. Análise à luz da judicialização, cit., p. 193 e 195.

${ }^{105} \mathrm{~A}$ solução para essa questão não é objeto do presente trabalho, no entanto, destacam-se os trabalhos de Dresch e Freitas nesse sentido. DRESCH, Renato Luís. op. cit.; FREITAS, Cristina Leitão Teixeira de. op. cit.

${ }^{106}$ SANTOS, Lenir. Judicialização da saúde e a incompreensão do SUS, cit., p. 147. No mesmo sentido DRESCH, Renato Luís. op. cit., p.135.

${ }^{107}$ WANG, Daniel Wei L. et al. op. cit., p. 1201.
} 
dos componentes estratégico e especializado, seja em situações em que, apesar da ausência de política pública e consequente não padronização, seria possível - em função do tipo de medicamento pleiteado e observando-se a sistemática de operacionalização da AF do SUS de acordo com níveis de complexidade (baixa, média e alta) - identificar o ente federativo com recursos financeiros para tanto ${ }^{108,109}$. A sobrecarga dos municípios ${ }^{110,111}$ ocorre em função de a condenação recair sobre ente federativo que possui "orçamentos menores e infraestrutura menos desenvolvida que os Estados e a União"112. Também resulta desse cenário o afastamento das regras de financiamento do SUS ${ }^{113}$.

A solidariedade, nos termos da interpretação judicial ora citada, leva à identificação de mais um efeito negativo: o fornecimento de medicação em duplicidade ou mesmo em triplicidade em casos de condenação que reputam solidária a obrigação de fornecer medicamentos ${ }^{114}$, levando à atuação sobreposta dos entes federativos ${ }^{115}$.

Outros efeitos negativos são: a inobservância da Lei n. 8.666/1993 (licitação) e da regulamentação da CMED, o que leva à compra direta ${ }^{116}$, desrespeitando as regras de gestão e a $\mathrm{PNM}^{117}$; e o desrespeito ao princípio da isonomia ${ }^{118}$, ao criar uma porta de entrada pelo Judiciário ${ }^{119}$, "um acesso desigual ao SUS ${ }^{120}$ - favorecendo aqueles que acionam o Judiciário"121.

Apesar dos pontos negativos levantados, a judicialização do direito à saúde tem sido considerada como incremento da cidadania e da democracia ${ }^{122}$ por possibilitar a concretização desse direito fundamental ${ }^{123}$.

O surgimento de iniciativas voltadas a orientar a atuação do Judiciário nas demandas de saúde ${ }^{124}$ tem provocado mudanças no cenário da judicialização. Ter-

\footnotetext{
${ }^{108}$ WANG, Daniel Wei L. et al. op. cit., p.1194; 1195.

${ }^{109}$ DRESCH, Renato Luís. op. cit.; FREITAS, Cristina Leitão Teixeira de. op. cit.

${ }^{110}$ FLEURY, Sonia; FARIA, Mariana. op. cit., p.106; 113-114.

${ }^{111}$ OLIVEIRA, L. V.op cit. p. 193.

${ }^{112}$ WANG, Daniel Wei L. et al. op. cit., p.1023-1024; 1194; 1201; ASENSI, Felipe. op. cit., p. 154-155.

${ }^{113}$ SCHULZE, Clenio Jair; GEBRAN NETO, João Pedro. Direito à saúde. Análise à luz da judicialização, cit., p. 155; CHIEFFI, Ana Luiza; SIQUEIRA, Paula Facundo de. op. cit., p. 286.

${ }^{114}$ BRASIL. Advocacia Geral da União. Consultoria Jurídica/Ministério da Saúde. Intervenção Judicial na saúde pública, cit.

${ }^{115}$ WANG, Daniel Wei L. et al. op. cit., p. 1195.

${ }^{116}$ SCHULZE, Clenio Jair; GEBRAN NETO, João Pedro. Direito à saúde. Análise à luz da judicialização, cit., p. 111.

${ }^{117}$ LEITE, Silvana Nair et al. op. cit., p.14; PEPE, Vera Lúcia Edais et al. op. cit., p. 3.

${ }^{118}$ Quando atua na perspectiva do direito individual, a judicialização da saúde “acaba por colaborar com a má distribuição destes escassos recursos". SCHULZE, Clenio Jair; GEBRAN NETO, João Pedro. Direito à saúde. Análise à luz da Judicialização, cit., p. 155; 138.

${ }^{119}$ SANTOS, Lenir. Judicialização da saúde e a incompreensão do SUS, cit., p.156.

${ }^{120}$ No debate sobre a isonomia é importante notar se o caso envolve medicamento padronizado ou não.

${ }^{121}$ WANG, Daniel Wei L. et al. op. cit., p. 1023-1024; 1201; PEPE, Vera Lúcia Edais et al. op. cit., p. 1.

${ }^{122}$ FLEURY, Sonia. Judicialização pode salvar o SUS, cit., p. 159.

${ }^{123}$ BORGES, Daniela da Costa Leite; UGÁ, Maria Alicia Dominguez. op. cit., p. 67.

${ }^{124}$ Apesar da importância desses novos eventos, eles não foram capazes de conter a judicialização da saúde ou melhorar os seus serviços ou financiamento. SANTOS, Lenir. Judicialização da saúde e a incompreensão do SUS, cit., p.155,156.
} 
razas destaca três novos eventos importantes nesse cenário: a Audiência Pública n. 4 do STF, de 2009, com resultados sintetizados na decisão da Suspensão de Tutela Antecipada n. 175/CE do STF; a edição da Recomendação n. 31 do Conselho Nacional de Justiça (CNJ), em 2010; e a Lei n. 12.401/2011 ${ }^{125}$, que alterou a Lei n. 8.080/1990126. Destacam-se, também, a Resolução n. 107/2010 do CNJ e os enunciados da saúde pública da I e da II Jornadas de Direito da Saúde ${ }^{127,128}$.

No Estado de Santa Catarina, tem-se como reflexo dessas orientações: a criação, em 2012, do Comitê Estadual de Monitoramento e Resolução das Demandas de Assistência da Saúde de Santa Catarina (Comesc), que tem enunciados na área da saúde pública; a instituição do Núcleo de Apoio Técnico (NAT), em 2015; no Município de São José, a Portaria n. 12/2012 da Vara da Fazenda Pública, Execução Fiscal Acidente de Trabalho e Registro Público, editada pelo juiz Paulo Roberto Froes Toniazzo.

Apesar de o estudo do conteúdo desses novos elementos e suas diretrizes não serem, diretamente, objeto de análise do presente trabalho, qualquer abordagem sobre a judicialização da saúde deve considerar sua existência.

\section{A operacionalização do SUS e de sua AF diante das decisões do TJSC em apelações cíveis do Município de São José}

Foram analisadas 37 decisões ${ }^{129}$ prolatadas pelo TJSC em apelações cíveis interpostas pelo Município de São José - selecionadas de acordo com os critérios de busca especificados na metodologia do presente artigo. Da análise, foram excluídas 20 decisões, sendo nove delas, por apresentarem matéria de análise não correspondente à delimitação da presente pesquisa; dez, em razão de a apelação ser apenas do Estado de Santa Catarina; e uma, pelo fato do município ser o apelado e não o apelante. Das 17 analisadas, seis consistiram em acórdãos e 11, em decisões monocráticas (Anexo A).

\footnotetext{
${ }^{125}$ Para SCHULZE essa lei alterou o cenário da judicialização. SCHULZE, Clenio Jair; GEBRAN NETO, João Pedro. Direito à saúde. Análise à luz da judicialização, cit., p.105.

${ }^{126}$ TERRAZAS, Fernanda. Novos elementos no cenário da judicialização da saúde: análise das decisões dos tribunais superiores. In: SANTOS, Lenir; TERRAZAS, Fernanda (Orgs.) Judicialização da saúde no Brasil. 1. ed. Campinas: Saberes Ed., 2014. p. 307.

${ }^{127}$ SCHULZE, Clenio Jair; GEBRAN NETO, João Pedro. Direito à saúde. Análise à luz da judicialização, cit., p. 87

${ }^{128}$ Aprovados em maio de 2014 e maio de 2015, respectivamente. CONSELHO NACIONAL DE JUSTIÇA. Enunciados aprovados na I Jornada de Direito da Saúde do Conselho Nacional de Justiça em 15 de maio de 2014 - São Paulo-SP. Disponivel em: <http://www.cnj.jus.br/images/ENUNCIADOS_APROVADOS_NA_JORNADA DE DIREITO_DA_SAUDE_\%2OPLENRIA_15_5_14_r.pdf>. Acesso em: 13 out. 2017. Id. Enunciados aprovados na II Jornada de Direito da Saúde. Disponível em: <http://www.cnj.jus.br/files/conteudo/destaques/arquivo/2015/ 05/96b5b10aec7e5954fcc1978473e4cd80.pdf>. Acesso em: 13 out. 2017.

${ }^{129}$ Tais decisões foram proferidas sob a égide do antigo Código de Processo Civil (CPC), de 1973, revogado pela Lei n. 13.105/2015. BRASIL. Lei n. 13.105, de 16 de março de 2016. Código de Processo Civil. Disponível em: <http://www.planalto.gov.br/ccivil_03/_ato2015-2018/2015/lei/I13105.htm>. Acesso em: 13 out. 2017.
} 
A partir da identificação dos efeitos negativos da judicialização sobre a operacionalização do SUS e sua AF, sistematizados no tópico III, busca-se identificar de que forma os efeitos negativos se manifestaram nas decisões do TJSC.

A premissa da qual se partiu - a não aplicação das políticas do SUS pelo TJSC - confirmou-se nas 17 decisões, todas com fundamentações que ratificam a condenação do município com base tão somente na $\mathrm{CF} / 88$ e, por vezes, na Constituição Estadual e na Lei n. 8.080/1990. Os fundamentos jurídicos mais utilizados foram: artigos $6^{\circ}$ e $196 \mathrm{da} \mathrm{CF} / 88$, artigo 153 da Constituição do Estado de SC e citação geral da Lei n. 8.080/1990 - seu artigo 6, inciso I, alínea "d", sobre AF integral, foi citado em menos da metade dos casos e, quando mencionado, as decisões não se referiram à definição de integralidade dada pela Lei n. 12.401/2011. Quando citado o artigo $198 \mathrm{da} \mathrm{CF} / 88$, que dispõe sobre o SUS, seu parágrafo $1^{\circ}$ foi evidenciado para fundamentar a solidariedade dos entes federativos. Nesse quadro, era de se esperar que as normas de baixa hierarquia não fossem consideradas nas decisões do TJSC.

Por não seguirem a sistemática da política de saúde, as decisões do TJSC não foram firmadas de acordo com um padrão que permita a identificação de importantes variáveis para o estudo da judicialização da AF do SUS, como é o caso da qualificação do termo "medicamento" como padronizado ou não; se padronizado, se é do componente básico, estratégico, especializado, hospitalar, oncológico etc.; se é experimental; se tem ou não registro na Anvisa. Esse pode ser um dos fatores que justificam não terem sido identificadas decisões com argumentos diferenciados que não pudessem ser encontrados, também, em outras decisões. Há a mesma lógica argumentativa, independentemente do tipo de medicamento ou caso clínico concreto ${ }^{130}$. Esse cenário dificultou a organização da análise de acordo com o tipo/qualificação do medicamento ${ }^{131}$.

Apesar dessa dificuldade, a análise global das decisões do TJSC constatou a ocorrência do primeiro efeito negativo: a concessão de medicamentos que não constam nas listas oficiais, com fundamentação principal baseada na prescrição médica, sem seguir critérios de uso racional, segurança e evidência científica. Em 11 decisões, a prescrição do médico foi mencionada para reconhecer a necessidade do

\footnotetext{
${ }^{130}$ Observou-se que as decisões, quando de alguma forma mencionaram situações relacionadas a medicamento não padronizado, apresentaram um posicionamento padrão de reconhecer o dever do Estado - União, estados, municípios e Distrito Federal - em conceder o medicamento independentemente de se tratar de medicamento não padronizado ou de previsão orçamentária, de modo que a não padronização não serve de empecilho para o Estado cumprir sua obrigação.

${ }^{131} \mathrm{~A}$ identificação como padronizado ou não padronizado, em alguns casos, só foi possível após uma leitura atenta dos argumentos do TJ e da defesa - apresentados no relatório da decisão. No Anexo A, em seis decisões - 3, 9, 10,11, 12 e 13, todas monocráticas -, não foi possível fazer uma identificação clara. Puderam ser identificadas nove decisões - 1, 2, 4, 5, 6, 7, 14, 15 e 16 - tratando de medicamento não padronizado, uma decisão - 17 - com requerimento de medicamento padronizado e não padronizado, e um caso de medicamento padronizado - decisão 8. O TJSC, em suas argumentações, também não se ocupou com as diferenciações entre o componente básico, estratégico, especializado ou oncológico da assistência farmacêutica.
} 
medicamento, sem terem sido mencionados maiores detalhes nem do caso clínico do paciente nem do medicamento requerido - não havendo referência às questões do uso racional e de segurança do medicamento; do registro na Anvisa; do papel da Conitec; do protocolo clínico; da comparação do medicamento requerido com aqueles disponibilizados pelo SUS; da medicina baseada em evidências etc. Em alguns casos, mencionam-se as provas apresentadas nos autos, sem ser possível, a partir da decisão do TJSC, identificar o que foi apresentado nelas. Assim, foram observadas situações em que: não há menção à prescrição médica, mencionam apenas o laudo pericial, afirmam a necessidade do medicamento pela prescrição do médico que acompanha o paciente. Vale destacar que as decisões do TJSC, em sua maioria, não se preocuparam em identificar se o médico prescritor é vinculado ao SUS ou à iniciativa privada, não dando relevância a questão tão importante para o sistema, que se relaciona com o tema do acesso ao sistema e a suas portas de entrada.

O segundo efeito negativo - a interpretação judicial da competência comum do artigo 23, inciso II, da CF/88 como responsabilidade solidária dos entes federativos - foi observado em todas as decisões examinadas. O TJSC, seja por meio de seus argumentos, seja por meio da jurisprudência citada, fundamenta-se, especialmente, no artigo 23, inciso II c/c o artigo 198 parágrafo $1^{\circ} \mathrm{da} C F / 88$, que dispõe que o SUS é financiado com recursos do orçamento da seguridade social, da União, dos estados, do Distrito Federal e dos municípios. Além disso, verificaram-se interpretações dessa solidariedade com base no Código Civil (apelações 2, 6 e 13 do Anexo A), o que também é incompatível com a sistemática do SUS.

A presença dessa interpretação leva à averiguação do terceiro efeito negativo nas decisões do TJ: a responsabilização dos municípios para fornecerem medicamentos que não são de sua competência. A dificuldade na identificação das decisões quanto ao medicamento padronizado (por competência da União ou do estado) ou não padronizado também afetou essa análise. Apesar disso, observou-se que em ao menos cinco decisões constam, no relatório, alegações do ente federativo no sentido de que o medicamento é do componente estratégico, consistindo, por isso, em um programa da União, cujo gerenciamento é feito pelo estado. No entanto, o TJ manteve as condenações do município sem levar em conta, em sua fundamentação, tais arguições. Ainda nos casos em que se identificou tratar-se de medicamento não padronizado, nenhuma menção foi feita à dispensação do medicamento de acordo com os graus de complexidade - baixa, média ou alta.

Ao ser mantida a condenação conjunta - com base na responsabilidade solidária - do estado e do município para o fornecimento dos medicamentos pleiteados em quatro decisões ${ }^{132}$, observa-se a ocorrência do quarto efeito negativo nas decisões do TJ: o fornecimento de medicação em duplicidade. Ao condenar ambos os entes,

\footnotetext{
${ }^{132} \mathrm{Na}$ Apelação 2013.05045-4 foi admitido o chamamento do Estado ao processo (Anexo A).
} 
essas decisões ${ }^{133}$ não criaram nenhum fluxo ou orientação para evitar que os dois cumprissem a mesma obrigação. A possibilidade de fornecimento em triplicidade não foi verificada nas decisões do TJSC, já que o chamamento da União ao processo foi afastado - tendo-se, inclusive, destacado essa medida como meramente protelatória ${ }^{134}$.

Além desses pontos analisados, observou-se que em, todas as 17 decisões do TJSC, (a) o objeto foi o requerimento de medicamentos, sem ter identificado reiterados pedidos de um mesmo fármaco; (b) o TJSC negou o provimento/seguimento da apelação, tendo sido mantida a condenação do município; (c) houve deferimento e posterior confirmação do pedido de tutela antecipada; (d) estavam a rever sentenças prolatadas em ações de cunho individual; e (e) está patente a influência do novo constitucionalismo.

\section{Considerações finais}

Atendendo ao que foi proposto no presente trabalho, identificou-se como os efeitos negativos da judicialização do direito à saúde sobre a operacionalização do SUS e de sua AF se manifestaram nas decisões prolatadas pelo TJSC nas apelações cíveis interpostas pelo Município de São José.

Verificou-se um cenário que reforça e pormenoriza o argumento de que, ao não respeitar as políticas públicas quando da efetivação do direito à saúde, o Judiciário colabora para a desorganização e desestruturação da já difícil e complexa sistemática de concretização do SUS. Essa constatação faz pensar que grande parte dos operadores do direito desconhece essa sistemática, situação que reflete, de um lado, a análise feita por Bucci ${ }^{135}$ de que as políticas públicas são estranhas ao mundo jurídico e, de outro, a necessidade de disseminação do Direito Sanitário. É preciso reconhecer que, à dificuldade de lidar com políticas públicas, acrescenta-se a dificuldade de se entender o SUS, como foi destacado.

Tão graves são as consequências desse fenômeno - sob o aspecto tanto administrativo/organizacional quanto financeiro -, que o município estudado chegou a buscar alternativas como: a inclusão de uma rubrica para a judicialização de medicamentos no orçamento público ${ }^{136}$ e a criação do Nutaj - antes mesmo dos NATs previstos pelo CNJ.

\footnotetext{
${ }^{133}$ Interessante relato de Cristina Leitão sobre decisões do Paraná que seguem os novos elementos do cenário da judicialização e se preocupam com as regras de competência no SUS. FREITAS, Cristina Leitão Teixeira de. op. cit., p. 87-93.

${ }^{134}$ Exemplo dos argumentos da Apelação 6 (Anexo A).

${ }^{135} \mathrm{BUCCl}$, Maria Paula Dallari. Direito administrativo e políticas públicas. 1. ed. 2. tir. São Paulo: Saraiva, 2006. p. 262; 257.

${ }^{136}$ ARRUDA, Alessandra Cristina Laurindo. A judicialização como meio de acesso ao direito fundamental à saúde e seus efeitos orçamentários: a realidade do município de São José/SC. 2012. Trabalho de Conclusão de Curso (Graduação em Direito) - Centro Universitário Estácio de Sá de Santa Catarina, São José-SC, 2012.
} 
Os prejuízos à operacionalização do SUS e de sua AF devem ser traduzidos, também, em termos institucionais e jurídicos. O SUS é uma instituição formada pelo conjunto de diversas outras que se articulam em rede, de forma descentralizada, regionalizada e hierarquizada, com participação da comunidade e cooperação intergestores, com o escopo de garantir o acesso universal, integral e equânime à saúde. Assim, as várias decisões judiciais que condenam o município sem observar as políticas públicas do SUS não têm efeito apenas local, e sim refletem-se em toda essa rede e ferem, ao mesmo tempo, uma instituição constitucional - o SUS - e o direito de todos à saúde -em sua dimensão coletiva e individual - que é viabilizado justamente por esse sistema.

A análise evidencia, então, a necessidade de o Judiciário atuar de modo a fazer com que o Estado cumpra o dever de garantir o direito à saúde de acordo com a sistemática de operacionalização do SUS, de forma que faça com que o SUS funcione, mas que funcione como SUS. Isso envolve a clamada conexão entre as dimensões política e jurídica, própria dos direitos sociais, e corrobora as exigências constitucionais da sistemática de efetivação do direito à saúde.

Sob essa perspectiva, a judicialização pode gerar efeitos positivos sobre a operacionalização do sistema de saúde e de sua AF. Para que isso ocorra, faz-se necessária uma nova racionalidade cooperativa e participativa ao se pensar e concretizar o direito à saúde. Diversos trabalhos científicos, assim como os recentes eventos no cenário judicialização da saúde, apontam o diálogo como um meio para se encontrar essa nova racionalidade.

No entanto, o caminho a se percorrer ainda é longo, o que fica demonstrado pela constatação - ainda que não seja objeto de análise mais detida do presente trabalho - de que as decisões do TJSC não fizeram referência expressa a nenhum desses recentes eventos, que se traduzem como tentativas de melhorar o panorama da judicialização da saúde no país ${ }^{137}$. Sequer a Lei n. 12.401/2011 foi citada.

Isso mostra que a preocupação não deve ser apenas com a existência do diálogo, mas também com a qualificação dele. Por isso, é importante colocar a operacionalização do SUS e de sua AF, em toda a sua complexidade, na pauta do diálogo.

A preocupação com a desestruturação e o enfraquecimento do SUS diante da judicialização se agrava em tempos de crise e ameaça de corte de orçamento para a saúde pública. Se o subfinanciamento do sistema sempre foi um dos fatores responsáveis pela distância entre o SUS legal e o SUS real, mudanças que agravem esse quadro têm a potencialidade de fazer com que surjam mais "falhas" no sistema e, consequentemente, mais ações visando a correções nele.

\footnotetext{
${ }^{137}$ Como exceção, notou-se que na Apelação 13 há menção à STA 175 do STF (Anexo A). No entanto, este instrumento foi citado apenas para discorrer sobre a teoria dos direitos fundamentais.
} 
Há que se destacar, ainda, que, no momento em que se revisa o presente artigo, já foi decido o IRDR instaurado no TJSC, que firmou várias teses jurídicas sobre o tema ora pesquisado. A importância de apresentar essa atualização dá-se em função, especialmente, dos efeitos provenientes ${ }^{138}$ desse novo instituto processual.

Do exposto, confirma-se que a possibilidade de se exigir judicialmente o direito à saúde é uma grande conquista possibilitada pelo Estado Democrático de Direito. No entanto, a concretização desse direito pela via judicial deve ser feita, sempre que possível, de acordo com a lógica de operacionalização do SUS, o que não correrá enquanto não houver um diálogo nos termos acima considerados.

\section{Referências}

AITH, Fernando. Curso de direito sanitário. A proteção do direito à saúde no Brasil. São Paulo: QuartierLatin, 2007.

APRESENTAÇÃO. Portal da Saúde. Disponível em: <http://portalsaude.saude.gov.br/ index.php/o-ministerio/principal/leia-mais-o-ministerio/1132-sctie-raiz/daf-raiz/cgafme/ 11-cgafme/11722-apresentacao $>$.

ARRUDA, Alessandra Cristina Laurindo. A judicialização como meio de acesso ao direito fundamental à saúde e seus efeitos orçamentários: a realidade do município de São José/SC. 2012. Trabalho de Conclusão de Curso (Graduação em Direito) - Centro Universitário Estácio de Sá de Santa Catarina, São José-SC, 2012.

ASENSI, Felipe. Responsabilidade solidária dos entes da Federação e "efeitos colaterais" no direito à saúde. Revista Direito Sanitário, São Paulo, v. 16, n. 3, p. 145-156, jun. 2016. Disponível em: <https://www.revistas.usp.br/rdisan/article/download/111658/109689>. Acesso em: 13 out. 2017. http://dx.doi.org/10.11606/issn.2316-9044.v16i3p145-156.

BORGES, Daniela da Costa Leite; UGÁ, Maria Alicia Dominguez. Conflitos e impasses da judicialização na obtenção de medicamentos: as decisões de 1a instância nas ações individuais contra o Estado do Rio de Janeiro, Brasil, em 2005. Caderno de Saúde Pública, Rio de Janeiro, v. 26, n. 1, p. 59-69, jan. 2010. Disponível em: <http://www.scielosp.org/pdf/csp/v26n1/07. pdf>. Acesso em: 13 out. 2017. http://dx.doi.org/10.1590/S0102-311X2010000100007.

BRASIL. Advocacia Geral da União. Consultoria Jurídica/Ministério da Saúde. Intervenção Judicial na saúde pública. Panorama no âmbito da Justiça Federal e Apontamentos na seara das Justiças Estaduais. 2013. Disponível em: <http://u.saude.gov.br/images/pdf/2014/maio/29/ Panorama-da-judicializa----o---2012---modificado-em-junho-de-2013.pdf>. Acesso em: 13 out. 2017.

\footnotetext{
138“Art. 985. Julgado o incidente, a tese jurídica será aplicada: I - a todos os processos individuais ou coletivos que versem sobre idêntica questão de direito e que tramitem na área de jurisdição do respectivo tribunal, inclusive àqueles que tramitem nos juizados especiais do respectivo Estado ou região; II - aos casos futuros que versem idêntica questão de direito e que venham a tramitar no território de competência do tribunal, salvo revisão na forma do art. 986." BRASIL. Lei 13.105 de 16 de março de 2015, cit.
} 
BRASIL. Conselho Nacional de Secretários de Saúde. Assistência Farmacêutica no SUS. Brasília: CONASS, 2011. (Coleção para entender a gestão do SUS, v. 7). Disponível em: <http://bvsms. saude.gov.br/bvs/publicacoes/para_entender_gestao_sus_v.7.pdf>. Acesso em: 13 out. 2017.

BRASIL. Ministério da Saúde. Secretaria de Ciência, Tecnologia e Insumos Estratégicos. Departamento de Assistência Farmacêutica e Insumos Estratégicos. Relação Nacional de Medicamentos Essenciais: RENAME 2014. 9. ed. - Brasília: Ministério da Saúde, 2015. Disponível em: <http://conitec.gov.br/images/Artigos_Publicacoes/Rename/Rename-2014Julho2015.pdf >. Acesso em: 13 out. 2017.

BUCCI, Maria Paula Dallari. Direito administrativo e políticas públicas. 1. ed. 2. tir. São Paulo: Saraiva, 2006.

CANOTILHO, J. J. Gomes. Direito Constitucional e teoria da Constituição. 7. ed. 6. reimp. Coimbra: Almedina, 2003.

CANUT, Letícia. Comissões Intergestores: inovação na descentralização das políticas de saúde. In: CUSTÓDIO, Ande Viana; VIEIRA, Reginaldo de Souza (Orgs.). Estado, política e direito políticas públicas e direitos sociais. Criciúma: UNESC, 2011. v. 3, p. 101-125.

Exercício do direito coletivo à saúde na pós-modernidade jurídico-política brasileira: nova estrutura participativa para a formulação das políticas do Sistema Único. 2013. Tese (Doutorado em Direito) - Programa de Pós-graduação em Direito - PPGD da Universidade Federal de Santa-Catarina, Florianópolis, 2013.

. Uma breve introdução ao SUS para compreensão do direito à saúde no Brasil. Revista Direitos Fundamentais \& Democracia (UniBrasil), Curitiba, v. 12, n. 12, p. 186-214, jul./dez. 2012. Disponível em: <http://revistaeletronicardfd.unibrasil.com.br/index.php/rdfd/article/ viewFile/311/281>.

CHIEFFI, Ana Luiza; SIQUEIRA, Paula Facundo de. Judicialização da saúde no Estado de São Paulo. In: In: SANTOS, Lenir; TERRAZAS, Fernanda (Orgs.). Judicialização da saúde no Brasil. 1. ed. Campinas: Saberes Ed., 2014.

CONSELHO NACIONAL DE JUSTIÇA. Enunciados aprovados na I Jornada de Direito da Saúde do Conselho Nacional de Justiça em 15 de maio de 2014 - São Paulo-SP. Disponível em: <http://www.cnj.jus.br/images/ENUNCIADOS_APROVADOS_NA_JORNADA_DE_ DIREITO_DA_SAUDE_\%20PLENRIA_15_5_14_r.pdf>. Acesso em: 13 out. 2017.

Enunciados aprovados na II Jornada de Direito da Saúde. Disponível em: <http:// www.cnj.jus.br/files/conteudo/destaques/arquivo/2015/05/96b5b10aec7e5954fcc1978473e4 cd80.pdf>. Acesso em: 13 out. 2017.

CONSELHO NACIONAL DE SAÚDE. Pactos pela saúde. Disponível em: <http://conselho. saude.gov.br/webpacto/>. Acesso em: 13 out. 2017. 
DRESCH, Renato Luís. Federalismo solidário: a responsabilidade dos entes federativos na área da saúde. In: SANTOS, Lenir; TERRAZAS, Fernanda (Orgs.) Judicialização da saúde no Brasil. 1. ed. Campinas: Saberes Ed., 2014.

FLEURY, Sonia. Judicialização pode salvar o SUS. Revista Saúde em Debate, Rio de Janeiro, v. 36, n. 93, p. 159-162, abr./jun. 2012. Disponível em: <https://www.almg.gov.br/export/ sites/default/acompanhe/eventos/hotsites/2015/ciclo_judicializacao_saude/documentos/ material_referencia/artigo_sonia_fleury.pdf>.

; FARIA, Mariana. A judicialização como ameaça e salvaguarda do SUS. In: SANTOS, Lenir; TERRAZAS, Fernanda (Orgs.) Judicialização da saúde no Brasil. 1. ed. Campinas: Saberes Ed., 2014.

FOLY, Silvia Lane Freitaset al. Judicialização do acesso a medicamentos no Município de Itaperuna-RJ: perfil das demandas. Saúde \& Transf. Social, Florianópolis, v. 7, n. 2, p. 51-68, 2016. Disponível em: <http://incubadora.periodicos.ufsc.br/index.php/saudeetransformacao/ article/view/4043/4548>. Acesso em: 13 out. 2017.

FREITAS, Cristina Leitão Teixeira de. Judicialização da saúde. Solidariedade e ressarcimento: destaques da posição dos estados frente à polarização de entendimentos. In: SANTOS, Lenir; TERRAZAS, Fernanda (Orgs.) Judicialização da saúde no Brasil. 1. ed. Campinas: Saberes Ed., 2014.

GEBRAN NETO, João Pedro. Direito constitucional à saúde e suas molduras jurídicas. In: SCHULZE, Clenio Jair; GEBRAN NETO, João Pedro. Direito à saúde. Análise à luz da judicialização. Porto Alegre: Verbo Jurídico, 2015.

LEITE, Silvana Nair et al. Ações Judiciais e demandas administrativas na garantia do direito de acesso a medicamentos em Florianópolis. Revista de Direito Sanitário, São Paulo. v. 10, n. 2, p. 13-28, jul./out. 2009. Disponível em: <http://www.revistas.usp.br/rdisan/article/ view/13161>. http://dx.doi.org/10.11606/issn.2316-9044.v10i2p13-28.

LUIZA, Vera Lucia et al.O medicamento na política de saúde no Brasil: como os agentes comunitários de saúde podem contribuir para a promoção do acesso e do uso racional de medicamentos? In: MATTA, Gustavo Corrêa; PONTES, Ana Lúcia de Moura (Orgs.) Políticas de saúde: operacionalização do Sistema único de Saúde. Rio de Janeiro: EPSJV; Fiocruz, 2007.

MACHADO, Marina Amaral de Ávila. Judicialização do acesso a medicamentos no Estado de Minas Gerais, Brasil. Revista Saúde Pública, v. 45, n. 3, p. 590-598, jun. 2011. Disponível em: <http://www.scielo.br/scielo.php?script=sci_arttext\&pid=S0034-89102011000300018>. http://dx.doi.org/10.1590/S0034-89102011005000015.

OLIVEIRA, Luciana da Veiga. Comitês Executivos da Saúde. In: SANTOS, Lenir; TERRAZAS, Fernanda (Orgs.) Judicialização da saúde no Brasil. 1. ed. Campinas: Saberes Ed., 2014.

PEPE, Vera Lúcia Edais et al. A judicialização da saúde e os novos desafios da gestão da assistência farmacêutica. Ciência \& Saúde Coletiva, v. 15, n. 5, p. 2405-2414, ago. 2010. Disponível em: <http://www.scielo.br/pdf/csc/v15n5/v15n5a15.pdf >. Acesso em: 13 out. 2017. http://dx.doi.org/10.1590/S1413-81232010000500015. 
RIBEIRO, J. S. et al. Judicialização da Saúde: direitos coletivos versus direitos individuais. In: PEREIRA, M. F. et al. (Org.). Contribuições para a gestão do SUS. Florianópolis: Fundação Boiteux, 2013. (Coleção Gestão da Saúde Pública, v. 4).

SANTOS, Lenir. A saga do direito à saúde: 28 anos de construção e desconstrução. Consultor Jurídico, 03 dez. 2016. Disponível em <http://www.conjur.com.br/2016-dez-03/lenir-santos28-anos-construcao-desconstrucao-direito-saude>. Acesso em: 13 out. 2017.

Judicialização da saúde e a incompreensão do SUS. In: SANTOS, Lenir; TERRAZAS, Fernanda (Orgs.) Judicialização da saúde no Brasil. 1. ed. Campinas: Saberes Ed., 2014.

. O princípio da solidariedade no SUS. Blog o Direito Sanitário: saúde e cidadania. Disponível em: <http://blogs.bvsalud.org/ds/2011/09/30/o-principio-da-solidariedade-nosus/>. Acesso em: 13 out. 2011.

; CARVALHO, André Luis Bonifácio. O impacto da judicialização sob a ótica da Comissão Intergestores Tripartite. 2014. In: SANTOS, Lenir; TERRAZAS, Fernanda (Orgs.) Judicialização da saúde no Brasil. 1. ed. Campinas: Saberes Ed., 2014.

SARLET, Ingo Wolfgang. A eficácia dos direitos fundamentais: uma teoria geral dos direitos fundamentais na perspectiva constitucional. 10. ed. rev. atual. e ampl. Porto Alegre: Livr. do Advogado, 2010.

SCHULZE, Clenio Jair; GEBRAN NETO, João Pedro. Direito à saúde: análise à luz da judicialização. Porto Alegre: Verbo Jurídico, 2015.

. Direito à saúde - novas perspectivas. In: SANTOS, Lenir; TERRAZAS, Fernanda (Orgs.) Judicialização da saúde no Brasil. 1. ed. Campinas: Saberes Ed., 2014.

TERRAZAS, Fernanda. Novos elementos no cenário da judicialização da saúde: análise das decisões dos tribunais superiores. In: SANTOS, Lenir; TERRAZAS, Fernanda (Orgs.) Judicialização da saúde no Brasil. 1. ed. Campinas: Saberes Ed., 2014.

WANG, Daniel Wei L. et al. Os impactos da judicialização da saúde no município de São Paulo: gasto público e organização federativa. Revista de Administração Pública, Rio de Janeiro, v. 48, n. 5, p. 1191-1206, set./out. 2014. Disponível em: <http://www.scielo.br/pdf/rap/v48n5/06. pdf>. http://dx.doi.org/10.1590/0034-76121666.

Letícia Canut - Doutora em Direito pela Universidade Federal de Santa Catarina e pela Escola Nacional de Saúde Pública da Universidade Nova de Lisboa; mestre em Direito pela UFSC; graduada em Direito pela Universidade Federal de Uberlândia. Professora do Centro Universitário Estácio Santa Catarina. Advogada. Florianópolis/SC, Brasil. E-mail: leticiacanut@hotmail.com. 


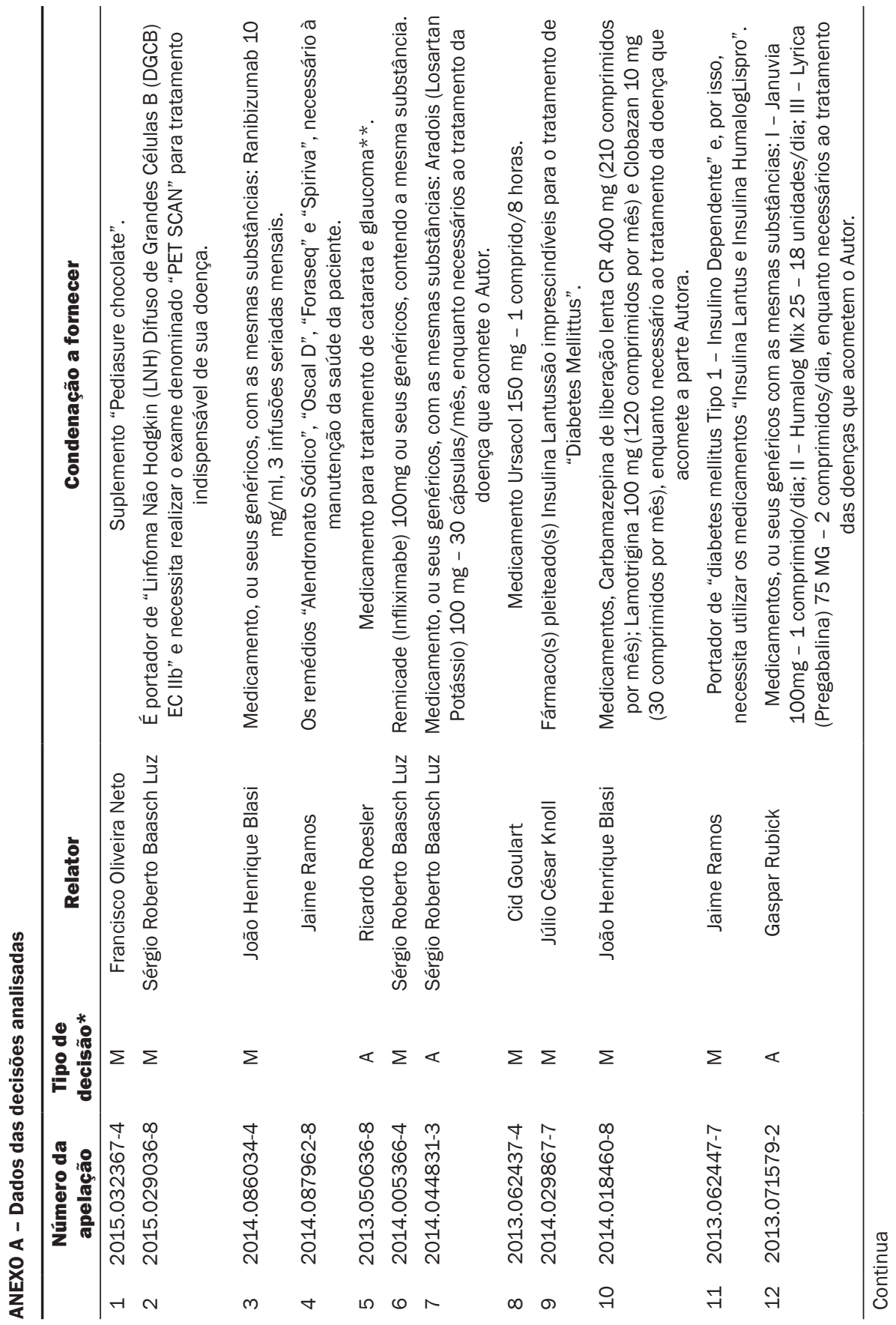




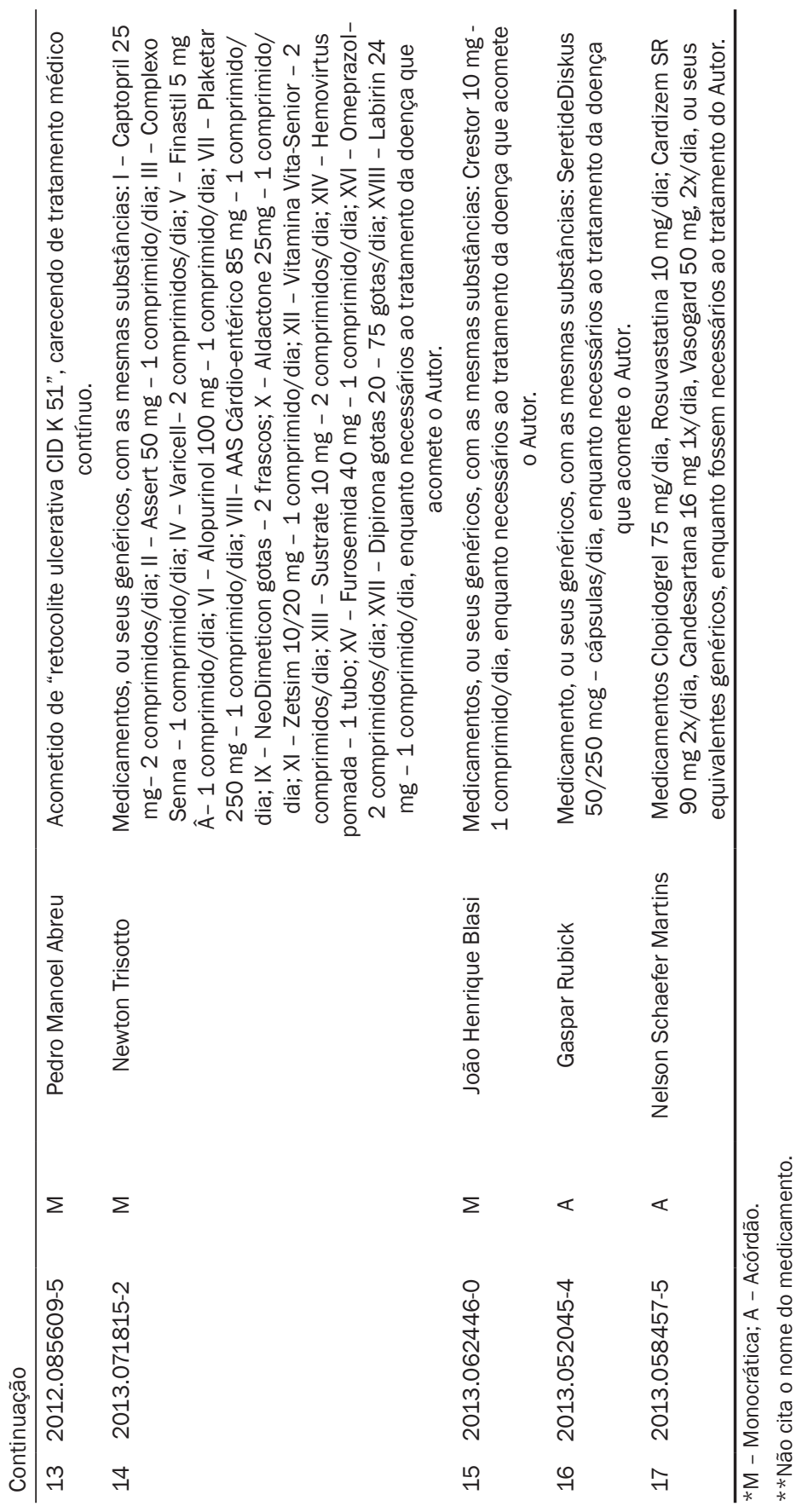

